\title{
Barriers to Enrollment in Health Coverage in Colorado
}

Laurie T. Martin, Nazleen Bharmal, Janice C. Blanchard, Melody Harvey, Malcolm V. Williams

Sponsored by the Colorado Health Foundation 
For more information on this publication, visit www.rand.org/t/rr782

Published by the RAND Corporation, Santa Monica, Calif.

(C) Copyright 2014 RAND Corporation

RAND $^{\circledR}$ is a registered trademark.

\section{Limited Print and Electronic Distribution Rights}

This document and trademark(s) contained herein are protected by law. This representation of RAND intellectual property is provided for noncommercial use only. Unauthorized posting of this publication online is prohibited. Permission is given to duplicate this document for personal use only, as long as it is unaltered and complete. Permission is required from RAND to reproduce, or reuse in another form, any of its research documents for commercial use. For information on reprint and linking permissions, please visit www.rand.org/pubs/permissions.html.

The RAND Corporation is a research organization that develops solutions to public policy challenges to help make communities throughout the world safer and more secure, healthier and more prosperous. RAND is nonprofit, nonpartisan, and committed to the public interest.

RAND's publications do not necessarily reflect the opinions of its research clients and sponsors.

Support RAND

Make a tax-deductible charitable contribution at www.rand.org/giving/contribute

www.rand.org 
In the spring of 2014, the Colorado Health Foundation asked RAND to examine reasons why people eligible for Medicaid and/or subsidized private insurance through Colorado's health insurance exchange (called Connect for Health Colorado) are not enrolled in health care coverage in Colorado. Using a conceptual framework to guide its efforts, RAND conducted focus groups with uninsured and newly insured individuals across the state and interviews with local stakeholders responsible for enrollment efforts in their regions. This report provides an overview of these findings, highlighting those that were consistent across the state and those that were unique to a given region or population.

This report should be of relevance to individuals and organizations within and outside of Colorado who have an interest in reducing barriers to insurance enrollment. It will also be of significance to funders, Connect for Health Colorado, and other organizations that may be in a position to support such efforts, both financially and otherwise. Finally, the report and its findings will be applicable to local stakeholders responsible for outreach and enrollment efforts in their communities.

This research was sponsored by the Colorado Health Foundation and conducted within RAND Health. A profile of RAND Health, abstracts of its publications, and ordering information can be found at www.rand.org/health. This research study was co-led by Laurie Martin and Malcolm Williams. Questions about the report may be directed to Laurie_Martin@rand.org or Malcolm_Williams@rand.org. 


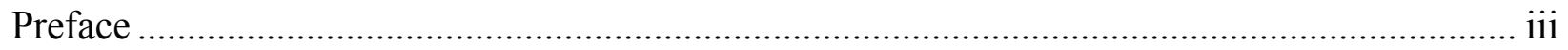

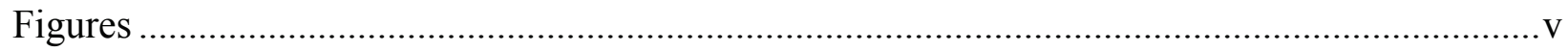

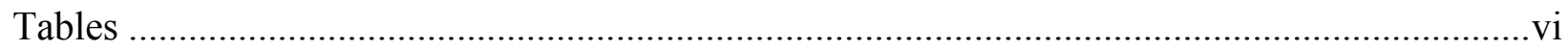

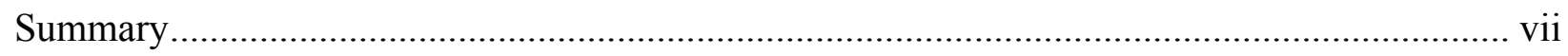

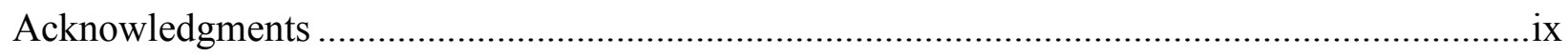

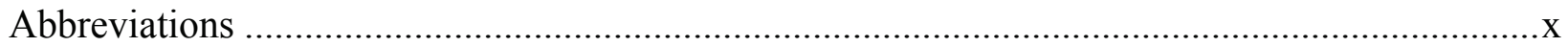

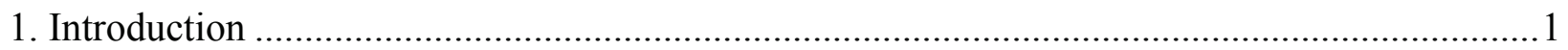

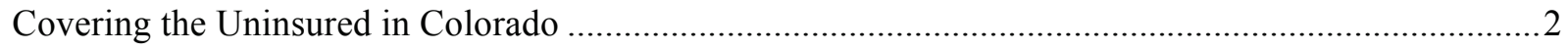

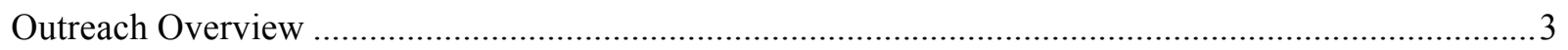

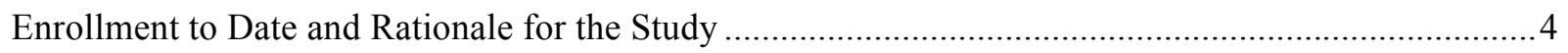

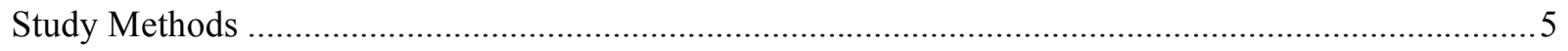

2. Barriers to Health Insurance Coverage Across Colorado...................................................9

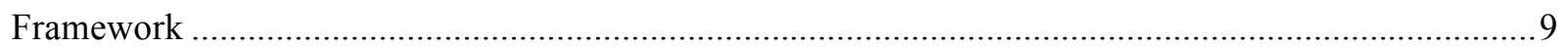

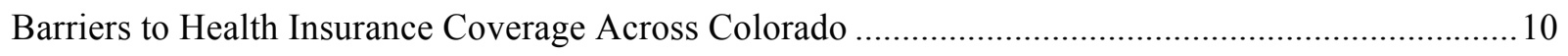

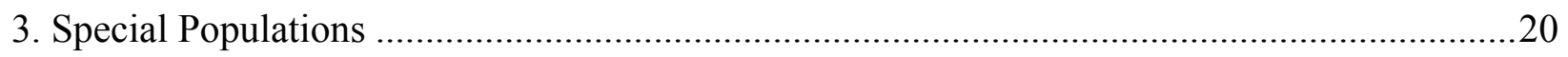

Spanish-Speaking Populations and Families of Mixed Immigration Status ......................................20

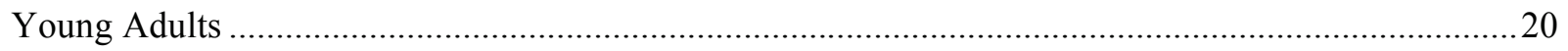

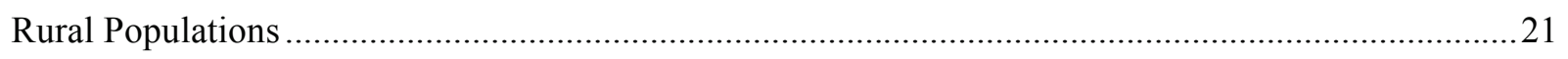

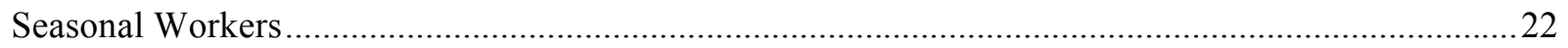

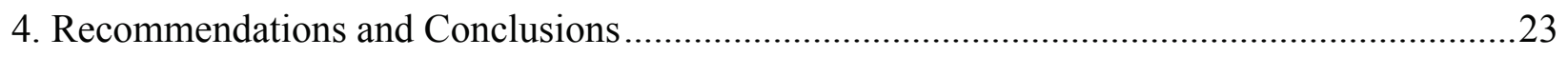

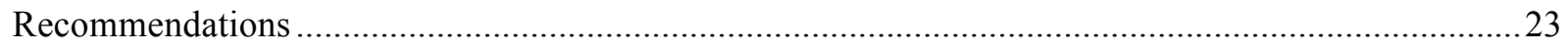

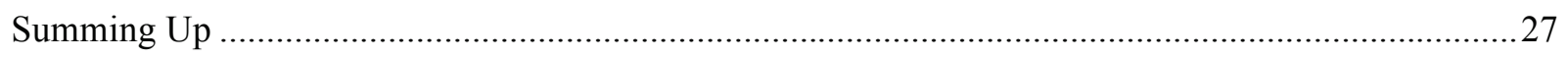

Appendix A. Barriers to Health Insurance Coverage-Metro Region......................................29

Appendix B. Barriers to Health Insurance Coverage - North Central Region.............................34

Appendix C. Barriers to Health Insurance Coverage - Northeast Region ..................................38

Appendix D. Barriers to Health Insurance Coverage - Central Region.....................................42

Appendix E. Barriers to Health Insurance Coverage - Southeast Region .................................45

Appendix F. Barriers to Health Insurance Coverage - West Central Region .............................49

Appendix G. Barriers to Health Insurance Coverage - Northwest Region ................................53

Appendix H. Barriers to Health Insurance Coverage — Southwest Region.................................59

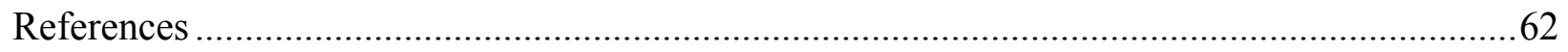




\section{Figures}

Figure A.1. Metro Region of Colorado and Location of Focus Groups (Denver, Colorado) .......30

Figure B.1. North Central Region of Colorado and Location of Focus Groups

(Fort Collins, Colorado)

Figure C.1. Northeast Region of Colorado and Location of Focus Groups

(Sterling, Colorado) .38

Figure D.1. Central Region of Colorado and Location of Focus Group

(Colorado Springs, Colorado)

Figure E.1. Southeast Region of Colorado and Location of Focus Groups

(Pueblo, Colorado)

Figure F.1. West Central Region of Colorado and Location of Focus Groups

(Grand Junction, Colorado)

Figure G.1. Northwest Region of Colorado and Location of Focus Groups

(Silverthorne, Colorado).

Figure H.1. Southwest Region of Colorado and Location of Interviews (Durango, Colorado)....59 


\section{Tables}

Table 1.1. Composition of Focus Groups Across Colorado...................................................... 7

Table 2.1. Framework for Insurance Coverage .................................................................. 9

Table 2.2. Barriers to Health Insurance Coverage Across Colorado.......................................... 10

Table 4.1. Recommendations to Address Enrollment Barriers ...................................................24

Table A.1. Barriers to Health Insurance Coverage in the Metro Region ...................................31

Table B.1. Barriers to Health Insurance Coverage in the North Central Region .........................36

Table C.1. Barriers to Health Insurance Coverage in the Northeast Region................................39

Table D.1. Barriers to Health Insurance Coverage in the Central Region .................................44

Table E.1. Barriers to Health Insurance Coverage in the Southeast Region...............................46

Table F.1. Barriers to Health Insurance Coverage in the West Central Region...........................50

Table G.1. Barriers to Health Insurance Coverage in the Northwest Region .............................55

Table H.1. Barriers to Health Insurance Coverage in the Southwest Region ............................60 


\section{Summary}

\section{Study Background, Purpose, and Approach}

In implementing the Patient Protection and Affordable Care Act (ACA), Colorado is one of 17 states $^{1}$ that decided to operate its own health insurance exchange for individuals (called Connect for Health Colorado) and one of 27 states to expand Medicaid (Kaiser Family Foundation, 2014). Colorado had more than 300,000 individuals newly enrolled in Medicaid (178,000 enrollments) or health insurance through the Marketplace (125,000 enrollments) between October 1, 2013, and March 31, 2014, with continued enrollments to date (Connect for Health Colorado, May 2014; U.S. Department of Health and Human Services, 2014). Among states that operated their own exchanges, Colorado had the fourth-highest number of people sign up for private insurance through the Marketplace during the first open enrollment period (25 percent of eligible individuals) (Kaiser Family Foundation, April 2014b). Despite this success, there continues to be a diverse mix of individuals in Colorado who remain eligible for but not enrolled in either private insurance or Medicaid. The Colorado Health Foundation commissioned the RAND Corporation to conduct a study to better understand why these individuals are not enrolled in health insurance coverage and to develop recommendations for how Colorado can strengthen its outreach and enrollment efforts during the next open enrollment period, which starts in November 2014.

RAND engaged a total of 108 uninsured or newly insured individuals who were representative of various regions and special populations across the state to understand their perspectives on why they had or had not enrolled in health insurance in Colorado. RAND also completed a total of 14 30-45-minute phone-based interviews with community stakeholders involved in the policymaking and insurance enrollment process who provided insight into outreach efforts in the community and barriers they perceive the uninsured face when seeking to enroll in health care coverage.

\section{Key Findings}

Respondents identified a number of barriers to enrollment. While there was some regional variability (additional detail on each region is provided in Appendixes $\mathrm{A}-\mathrm{H}$ of this report), there was a high level of concordance across regions as to the major barriers to enrollment and reasons why individuals were not enrolling. We grouped these barriers into three categories: those related to outreach and general awareness of health insurance and health insurance reform, those that affected the decision to enroll, and those that affected the enrollment process.

\footnotetext{
${ }^{1}$ Includes the District of Columbia.
} 
Barriers that affected outreach and awareness:

- Significant confusion and little understanding about Medicaid and private insurance subsidies through the Marketplace

- Messaging consumers were hearing (e.g., from media, politicians, stakeholders) about insurance was not compelling and did not discuss the health benefits of insurance

- Not enough funds or data to support local outreach and education.

Barriers that affected the decision to enroll:

- Unfavorable attitudes toward the individual mandate

- Significant mistrust of the system

- Messaging was often not tailored or actionable

- Health insurance coverage is not affordable.

Barriers that affected the enrollment process:

- Complexity of plan materials makes plan selection difficult

- Lag times and poor communication about eligibility-related decisions

- Misinformation across stakeholders

- Must apply for Medicaid and be denied before applying for private insurance

- Connect for Health Colorado website was not user-friendly.

\section{Recommendations}

A closer examination of the barriers to outreach and enrollment that were identified suggests that many are related. Collectively, they point to a set of four priority recommendations that stakeholders in Colorado may wish to consider:

1. Support and expand localized outreach and tailored messaging.

2. Revise marketing and messaging to be (1) clear, (2) actionable, and (3) focused on the health benefits of insurance (to overcome negative or politicized messaging consumers are hearing).

3. Improve the clarity and transparency of insurance and health care costs and enrollment procedures.

4. Revisit the two-stage enrollment process and improve Connect for Health Colorado website navigation and technical support.

Though outside the scope of this report, it may also be beneficial to examine how funds were disbursed across the state and how assistance sites that received federal and private grant funding allocated it to accomplish their objectives. This information may help to shed light on the current study findings and may help to inform future investments to maximize return. It should be noted that given the lag time between our data collection efforts in late June 2014 and the release of this report, Connect for Health Colorado or other stakeholders within Colorado may have already begun to address one or more of the barriers listed above. 


\section{Acknowledgments}

There are several individuals whom we wish to thank for their support in this study. First, we are grateful to Amy Kerr, Kelci Price, Amy Latham, and Kyle Sargent from the Colorado Health Foundation for inviting RAND to conduct this study and for providing helpful feedback throughout the project. Also, this work could not have been completed without the input from the uninsured and newly insured individuals in Colorado with whom we spoke, who shared their stories, perspectives, and recommendations for strengthening outreach and enrollment efforts in Colorado. We would also like to show our appreciation to the local stakeholders who provided their perspective and, in many cases, provided a space for us to conduct our focus groups. We learned a great deal from each of these individuals over the course of the project. We would also like to thank Resolution Research for their assistance with recruitment for the focus groups.

We acknowledge the support of RAND colleagues in carrying out our activities: Karen Florez and Christian Lopez, whose assistance enabled us to conduct two of the focus groups in Spanish, and Teague Ruder, who created the maps of Colorado used throughout this report. We also thank our peer reviewers, Anita Chandra, Carole Gresenz, and Jeanne Ringel, for their constructive feedback that helped to strengthen this report. We are also grateful to our communications analyst, David Adamson, and production editor, Steve Oshiro, for their contributions and care in helping us to complete this report. 


\section{Abbreviations}

ACA

$\mathrm{CHP}+/ \mathrm{CHPP}$

COBRA

CMS

ED

FPL

PEAK

$\mathrm{MCO}$

SHOP
Patient Protection and Affordable Care Act

Children's Health Plan Plus

Consolidated Omnibus Budget Reconciliation Act

Centers for Medicare and Medicaid Services

emergency department

federal poverty level

Program Eligibility and Application Kit

managed care organization

small business health options 


\section{Introduction}

One of the central goals of the Patient Protection and Affordable Care Act (ACA) is to extend health insurance to the uninsured and improve access to affordable health care. Two of the main ways that ACA extends health care coverage are through the expansion of public insurance and modifications to the private health insurance market, including the establishment of health insurance marketplaces or exchanges. Although the ACA is national in its scope, much of the critical action is taking place at the state level.

ACA expands public insurance by allowing states to extend Medicaid eligibility to individuals with an income below 138 percent of the federal poverty level (FPL) and offering federal subsidies to states to cover most of the costs associated with insuring those newly eligible for public insurance (RAND Corporation, 2014).

The ACA also allows states to establish their own exchanges, also known as state-based marketplaces, to facilitate the purchase of health insurance for eligible individuals and small businesses (Kaiser Family Foundation, April 2013). ${ }^{2}$ The marketplaces are intended for American citizens and legal residents who are ineligible for public health insurance (i.e., Medicaid, Children's Health Plan Plus [CHP+]) and who do not have an offer of creditable employer-sponsored health care coverage. Marketplaces are designed to make purchasing an individual health insurance plan easier by (1) standardizing offerings with bronze, silver, gold, and platinum plans that have defined actuarial values and cover, at a minimum, a number of specified "essential health benefits" and (2) increasing the transparency of price and quality differences across plans. Catastrophic health insurance plans are also available for people under 30 and people with hardship exemptions. ACA provisions require guaranteed issue and renewability of plans purchased through exchanges and remove preexisting condition exclusions and waiting periods. These provisions are intended to ensure the availability of coverage to individuals regardless of health status and expected health costs (Kaiser Family Foundation, April 2013).

The ACA provides consumers subsidies for the purchase of exchange-based plans for individuals with incomes between 100 percent and 400 percent of the $\mathrm{FPL}^{3}$ who are ineligible for Medicaid and have no affordable employer offer. ${ }^{4}$ In addition, the ACA precludes insurers from

\footnotetext{
${ }^{2}$ States that have chosen not to facilitate their own exchanges have either partnered with the federal government to run exchanges or have federally facilitated exchanges.

32014 federal poverty levels: 138 percent is $\$ 32,913$ for a family of four. Subsidies are available up to 400 percent of the FPL, which is $\$ 95,400$ for a family of four. States use a modified adjusted gross income formula.

${ }^{4}$ The legality of affording tax credits to eligible individuals who purchased health insurance through a federal exchange is being called into question, based on an interpretation of statutory language in the ACA (the legality of tax credits for individuals who purchased health insurance through state exchanges, including Colorado, is not being
} 
setting premiums that vary across individuals other than by age, region, family structure, and smoking status; limits the amount of variation in premium by age; and requires regulatory review of annual health insurance premium increases (Centers for Medicare and Medicaid Services, 2014b). The ACA imposes a penalty on individuals who are not covered by insurance, with some exceptions, such as for undocumented immigrants and individuals who would have to pay a premium that was greater than a specified share of their income (Kaiser Family Foundation, April 2013). The penalty in 2014 is $\$ 95$ per adult and half that amount per child, up to a maximum of $\$ 280$ per family or 1 percent of family income, whichever is greater (Kaiser Family Foundation, 2013a).

\section{Covering the Uninsured in Colorado}

Colorado is one of 17 states $^{5}$ with its own Marketplace (Kaiser Family Foundation, 2014) and one of 27 states that opted to expand Medicaid to low-income adults (Kaiser Family Foundation, 2014). Individuals can sign up for Medicaid or private insurance through the Health Insurance Marketplace, depending on their eligibility.

Prior to 2014, it was estimated that 737,000 individuals in Colorado were uninsured. Of these, 34 percent were Medicaid-eligible adults, 12 percent were Medicaid- or CHP+-eligible children, and 22 percent were eligible for tax-credit subsidies (33 percent were not eligible for financial assistance) (Kaiser Family Foundation, April 2014a). It is estimated that undocumented immigrants and their children account for about 4 percent of Colorado's overall population; undocumented immigrants are not eligible for Medicaid or insurance through the Marketplace (Camarota, August 2012).

\section{Medicaid}

In addition to expanding eligibility for Medicaid to up to 138 percent of the FPL in adults aged 19-64, Colorado continues to offer Medicaid to eligible children and pregnant women up to 147 percent of the FPL. Low-income children and pregnant women with household incomes up to 260 percent of the FPL and who are not eligible for Medicaid may qualify for CHP+, Colorado's state child health insurance program (Child Health Plan Plus, 2014). Colorado was an early implementer of Medicaid expansion and expanded coverage to low-income adults in 2012 under a Section 1115 research and demonstration waiver; this waiver extended Medicaid coverage to a small sample of childless adults with incomes up to 10 percent of the FPL (capped at 10,000 persons) prior to the implementation period of the ACA (Colorado Department of Health Care Policy and Financing, 2013; Courtot \& Coughlin, 2013).

debated). Two Circuits (the D.C. Circuit Court of Appeals in Washington and the 4th Circuit in Richmond, Virginia) reached differing conclusions on July 21, 2014 (James, 2014), continuing the debate over the legality of subsidies under the ACA.

${ }^{5}$ Including the District of Columbia. 
An estimated 258,000 Colorado residents were estimated to be eligible for Medicaid but not enrolled at the start of Medicaid expansion in January 2014; 210,000 of these individuals were newly eligible based on the expanded ACA criteria (Colorado Health Institute, 2014b).

\section{Health Insurance Marketplace}

The Colorado Health Benefit Exchange was signed into law in June 2011. Colorado's online exchange, now called Connect for Health Colorado, operates as a clearinghouse in which carriers can offer plans for consumers competitively. Although carriers can also offer plans outside the exchange directly to consumers, subsidies, provided in the form of tax credits, are available only when insurance is purchased through the exchange. Connect for Health Colorado offers both an individual marketplace and a small business health options (SHOP) marketplace, which helps businesses provide health coverage to their employees. As of June 2014, ten carriers offered 242 plans on the individual market, and eight carriers offered 92 plans on the SHOP marketplace (Colorado Department of Regulatory Agencies, 2014; Kaiser Family Foundation, November 2013). In the first open enrollment period, in order to get the subsidy, applicants had to first be evaluated for Medicaid eligibility through the Program Eligibility and Application Kit (PEAK) online process. Only after denial from Medicaid could an individual apply for the tax credits for the purchase of health insurance through the Marketplace.

\section{Outreach Overview}

As part of ACA implementation, state-based marketplaces can provide several types of consumer assistance to facilitate health care coverage enrollment (Centers for Medicare and Medicaid Services, 2014a). The goal of consumer assistance is to provide outreach and education to residents to raise awareness about the Marketplace, to prepare applications to establish eligibility and enroll in coverage through the Marketplace, and to offer other application and enrollment support. State-based marketplaces, like Colorado's, offer consumer assistance through a variety of mechanisms that often overlap in function but differ in the ways in which they are funded: (1) navigators, whose training can be funded by the federal government but whose compensation is funded by state and private grants; (2) in-person consumer assistants, who have similar functions as navigators but may be supported by state-administered (federally funded) Exchange Establishment grants; (3) certified application counselors (individuals and organizations). who may be federally funded and have some of the same roles as navigators and consumer assistants but who often are situated within existing health care or social service facilities; and (4) agents/brokers, who are compensated by insurance companies or consumers, consistent with state law (Centers for Medicare and Medicaid Services, 2014a). Regardless of funding support, most states report little difference among the types of services and assistance provided to consumers - particularly between navigators and in-person assistants (Dash, Lucia, Keith, \& Monahan, 2013). 
In Colorado, consumer assistance is organized into the Connect for Health Colorado Assistance Network, with navigators and in-person assistants collectively referred to as health coverage guides. Connect for Health Colorado (the Colorado Marketplace) issued a request for proposals for community-based organizations to serve as assistance sites and regional assistance hubs. Regional hubs share best practices and coordinate outreach efforts across the assistance sites in their region, and some provide support and training for assistance sites throughout their region and assist with communications efforts throughout the Assistance Network. Assistance sites hire, train, and supervise health coverage guides, who perform in-person education and application assistance services. Connect for Health Colorado contracted with 54 organizations to provide services within the Assistance Network, with five of these sites also operating as regional hubs (one additional organization serves only as a regional hub). Connect for Health Colorado awarded approximately \$16 million to support these efforts (Connect for Health Colorado, August 2014). Additional funding was made available through private grants, including funds from the Colorado Health Foundation. Assistance sites are composed of community/nonprofit and faith-based groups, hospitals and clinics, public health or human service organizations, and trade associations. The majority of these organizations have an established role in the communities they serve; some provide direct health care services. In addition, many community-based organizations that are not official Connect for Health Colorado assistance sites have certified health application counselors on their premises. Health coverage guides provide services at more than 75 locations throughout the state. At the start of open enrollment, the Assistance Network had 1,400 licensed and certified health insurance agents/brokers who provide advice and support with health insurance enrollment; this number had grown to over 1,500 by August, 2014 (Connect for Health Colorado, 2013; Kaiser Family Foundation, November 2013).

By the end of open enrollment (April 2013-June 2014), Colorado spent about $\$ 8$ million to market its health insurance exchange (Connect for Health Colorado, August 2014). This campaign consisted of media advertisements and direct outreach, including paid (e.g., radio, television) and earned media (e.g., journalistic coverage); Internet and social media; and inperson outreach to drive interest in enrollment.

\section{Enrollment to Date and Rationale for the Study}

More than 310,000 Coloradans had signed up or were approved for health insurance by the end

of the first open enrollment period (Kaiser Family Foundation, April 2014b). Between October 1, 2013, and March 31, 2014, 178,504 Coloradoans had newly enrolled in Medicaid and CHP+.

During this same period, 125,402 Coloradans enrolled in Marketplace plans (U.S. Department of Health and Human Services, 2014), with 134,950 Coloradans enrolled as of May 2014 (Connect for Health Colorado, May 2014). Prior to open enrollment, the Centers for Medicare and Medicaid Services (CMS) established state targets for Marketplace enrollment; the CMS target 
for Colorado was 92,000. Colorado exceeded the CMS-identified state target by more than 30 percent (Connect for Health Colorado, April 2014).

Despite this success, there continues to be a diverse mix of individuals who are eligible for but not enrolled in health care coverage. For example, Colorado's Southeast region had the lowest percentage of Marketplace enrollments among eligible individuals who qualify for a tax credit (25 percent), compared with other regions Colorado (Colorado Health Institute, 2014a). In addition, adult enrollees between the ages of 55 and 64 were more likely to enroll in Medicaid or the Marketplace than individuals between the ages of 19 and 29 (55 percent vs. 45 percent, respectively) (Colorado Department of Health Care Policy and Financing, April 2014a; Colorado Health Institute, 2014a).

The Colorado Health Foundation commissioned the RAND Corporation to conduct a study to better understand reasons why eligible individuals are not enrolled in health insurance coverage and to develop recommendations for how Colorado can strengthen its outreach and enrollment efforts during the next open enrollment period, which starts November 2014.

\section{Study Methods}

RAND engaged consumers and stakeholders involved in the policymaking and insurance enrollment process throughout the state to better understand factors affecting enrollment. This occurred through focus groups with uninsured and newly insured individuals and semistructured interviews with local stakeholders. This report focuses on individuals eligible for insurance through the Marketplace and through Medicaid. We did not emphasize views from populations ineligible to obtain insurance through these mechanisms (such as undocumented residents) or from individuals who refused employer-sponsored insurance options, although both views are important. However, some of our focus groups did include perspectives from families with mixed immigration status (mixed-status families), in which at least one person in the family is undocumented; those findings are discussed in the report.

Our key objectives were as follows:

- Examine elements of the outreach and enrollment approach and strategy.

- Explore barriers and facilitators to outreach and enrollment from both the consumer and stakeholder perspectives.

- Understand contextual or social factors contributing to or impeding success, including the social and political climates.

- Explore opportunities to improve the outreach and enrollment process.

\section{Consumer Focus Groups}

RAND engaged a total of 108 uninsured or newly insured individuals to understand their perspectives on why they had or had not enrolled in health insurance in Colorado. In partnership with the Colorado Health Foundation and using National Center for Health Statistics data, 
RAND identified eight regions across Colorado to conduct consumer focus groups during the last two weeks of June 2014. The regions were originally based on those outlined by the Colorado Department of Public Health and Environment, but modified slightly to capture the North Central region (Colorado Department of Public Health and Environment, 2014) (see Appendixes A-H). Focus groups varied by insurance gaps, special populations of interest (e.g., Spanish-speaking immigrants), and location within the state (e.g., urban, rural) to capture a diverse mix of views. Three focus groups were held in Denver ( $\mathrm{n}=41$; one of the groups was conducted in Spanish), two in Grand Junction ( $\mathrm{n}=9$ ), two in Silverthorne ( $\mathrm{n}=13$ across two groups; one was conducted in Spanish), and one each in Colorado Springs ( $\mathrm{n}=13)$, Fort Collins $(\mathrm{n}=13)$, Pueblo $(\mathrm{n}=11)$, and Sterling $(\mathrm{n}=4)$. In addition, we conducted four individual interviews with consumers from La Plata in lieu of a focus group, given participants' inability to attend the focus group on the designated date and time. As shown in Table 1.1, we sought to recruit a specific target demographic in each focus group to ensure representation from a diverse mix of special populations in addition to having regional representation. More information on each of the focus groups can be found in Appendixes A-H.

Focus group participants were adults younger than 65 who were either (1) eligible for but not enrolled in health care coverage in Colorado or (2) newly insured through Medicaid or the Marketplace with subsidies (e.g., signed up during open enrollment 2014). Though the emphasis of this report is on understanding reasons why individuals have not enrolled, the newly insured provided an important perspective, in that they progressed through every step needed to obtain coverage and could report on challenges with the enrollment process itself. Further, many had eligible but uninsured spouses or family. As a result, many were also able to provide a unique perspective on the barriers faced by families with mixed immigration status.

Individuals were recruited with the help of a Colorado-based recruitment firm, which disseminated information about the study in our regions of interest and conducted screeners to identify uninsured or newly insured individuals that met the preselected demographic criteria for that region (Table 1.1). We also relied on local community-based organizations for assistance in reaching Spanish-speaking individuals and other harder-to-reach populations. Host locations for the focus groups included community-based organizations or Marketplace assistance sites, a public library, and a local community college. In our focus groups, we explored a number of key themes:

- Knowledge, awareness, and understanding of health insurance

- Perceptions of health insurance

- Behaviors regarding and barriers to enrollment in health insurance

- Outreach and enrollment strategies

- Opportunities to streamline processes, remove barriers, and/or make enrollment more efficient. 
Table 1.1. Composition of Focus Groups Across Colorado

\begin{tabular}{|c|c|c|c|c|c|c|c|}
\hline Location (Region) & $\begin{array}{l}\text { Spanish- } \\
\text { Speaking }\end{array}$ & $\begin{array}{l}\text { Mixed } \\
\text { Race } \\
\text { and } \\
\text { Ethnicity }\end{array}$ & $\begin{array}{c}\text { African } \\
\text { American }\end{array}$ & Hispanic & $\begin{array}{l}\text { Parents } \\
\text { with } \\
\text { Eligible } \\
\text { Children }\end{array}$ & $\begin{array}{l}\text { Younger } \\
\text { Individuals } \\
(21-29 \\
\text { Years of } \\
\text { Age) }\end{array}$ & $\begin{array}{l}\text { Seasonal } \\
\text { Workers }\end{array}$ \\
\hline Colorado Springs (Central) & & & $x$ & $x$ & & & \\
\hline Denver (Metro) & & & $\mathrm{X}$ & & & $x$ & \\
\hline Denver (Metro) & $x$ & & & $x$ & & $x$ & \\
\hline Denver (Metro) & & $\mathrm{X}$ & & & & & \\
\hline Durango (Southwest) & & $x$ & & & & & \\
\hline Fort Collins (North Central) & & $x$ & & & & $x$ & \\
\hline $\begin{array}{l}\text { Grand Junction } \\
\text { (West Central) }\end{array}$ & & $x$ & & & $x$ & & \\
\hline $\begin{array}{l}\text { Grand Junction } \\
\text { (West Central) }\end{array}$ & & $x$ & & & & & \\
\hline Pueblo (Southeast) & & & $x$ & $x$ & $x$ & & \\
\hline Silverthorne (Northwest) & $x$ & & & $x$ & & & $x$ \\
\hline Silverthorne (Northwest) & & $X$ & & & & & $\mathrm{X}$ \\
\hline Sterling (Northeast) & & $\mathrm{X}$ & & & & & \\
\hline
\end{tabular}

\section{Stakeholder Interviews}

In partnership with the Colorado Health Foundation, RAND identified a potential list of state and local policymakers and community organizations invested in or leading outreach and enrollment efforts at the local level. We included organizations that were assistance sites for Connect for Health Colorado in various regions.

Using a semistructured interview protocol, we completed a total of 14 30-45-minute phonebased interviews with stakeholders during the first two weeks of July 2014. In our interviews, we explored a number of key themes:

- Elements of the outreach and enrollment approach and strategy

- Populations or geographies that have responded particularly well (or not) to the approach

- Partnerships or collaborations involved in the effort and those that would strengthen the effort

- Evidence of the effectiveness of the strategy

- Administrative or logistical facilitators and barriers

- Opportunities to streamline processes, remove barriers, and/or make enrollment more efficient.

In this report, we present our findings. We used content analysis to analyze themes and identify meaningful quotes from the stakeholder interviews and consumer focus groups (Krippendorff, 2012). In Chapter Two, we discuss general barriers and challenges to enrollment 
that existed universally across the state. Chapter Three provides findings specific to a number of special populations. Chapter Four presents our recommendations and conclusions. Given the diversity of Colorado in terms of populations and local context, we present findings by region in Appendixes A-H. It is important to note that while the locations of the focus groups were selected to be largely representative of that region, we conducted at most three focus groups in any one region, and as a result the findings and recommendations should supplement, not supplant, local knowledge of outreach and enrollment efforts. 


\section{Barriers to Health Insurance Coverage Across Colorado}

\section{Framework}

To help guide our thinking on the why individuals in Colorado were not enrolling in health insurance coverage, we developed a high-level framework (See Table 2.1). This framework suggests three key steps in the pathway toward insurance coverage: awareness of health insurance coverage and eligibility, the decision to enroll, and successful navigation of the enrollment process. Within each step, there is an interaction between the individual (e.g., his or her skills, experiences, and beliefs) and the operational, or structural, aspects of outreach and enrollment that are related to the Marketplace or conducted by individuals providing enrollment assistance (e.g., messaging, Connect for Health Colorado website).

Table 2.1. Framework for Insurance Coverage

\begin{tabular}{|c|c|c|c|}
\hline & Awareness & Decision to enroll & Enrollment process \\
\hline Individual & $\begin{array}{l}\text { - Health literacy } \\
\text { skills } \\
\text { - Integration into } \\
\text { community }\end{array}$ & $\begin{array}{l}\text { - Knowledge, } \\
\text { - } \text { attitudes, beliefs } \\
\text { - } \text { Stigma } \\
\text { - Practical barriers }\end{array}$ & $\begin{array}{l}\text { - Health literacy } \\
\text { skills } \\
\text { - Time and patience }\end{array}$ \\
\hline Operational & $\begin{array}{l}\text { - } \text { Clarity of message } \\
\text { - Tone/focus of } \\
\text { message } \\
\text { - Reach of message } \\
\text { - Messenger }\end{array}$ & $\begin{array}{l}\text { - Actionable } \\
\text { messaging } \\
\text { - Ease of access to } \\
\text { enrollment } \\
\text { assistance }\end{array}$ & $\begin{array}{l}\text { - } \text { Clear procedures } \\
\text { - Open } \\
\text { communication } \\
\text { - Working } \\
\text { infrastructure } \\
\text { - Adequate staff }\end{array}$ \\
\hline
\end{tabular}

Awareness, for example, will increase if the outreach and messages being delivered are clear and compelling, delivered by a trusted messenger, and disseminated in ways that will reach the intended audiences. But awareness also relies on the health literacy skills of the individual (i.e., the ability to find, understand, and apply information to make health-related decisions) and how well integrated the individual is in the community. Individuals who are connected to community or social service organizations, or who have a larger social network, are more likely to come in contact with information and messages about health insurance and its value.

Once an individual becomes aware of his or her health insurance options, he or she must decide to enroll. This decision not only draws on one's knowledge, attitudes, and beliefs about health and health care, but is also influenced by other factors, such as one's culture, perceptions 
of government assistance (e.g., stigma), and other practical barriers and tensions, such as cost. A number of operational factors may facilitate this decision, however, including the availability of clear and actionable messaging that tells individuals how to enroll or where to go for assistance once they have decided to enroll.

The enrollment process itself also relies heavily on an individual's health literacy skills and their ability to navigate the enrollment system, fill out or provide relevant information or paperwork, and make decisions about which plan to select. The enrollment process is not always easy or straightforward, and as a result it may require time and patience. Operational factors, including processes and infrastructure (e.g., website), may also affect enrollment outcomes.

\section{Barriers to Health Insurance Coverage Across Colorado}

Findings from this project suggest that significant barriers exist within each step of this process (as identified in Table 2.2). This chapter provides information on those barriers that were reported universally across all regions of Colorado, with additional detail by region presented in Appendixes A-H.

Table 2.2. Barriers to Health Insurance Coverage Across Colorado

\begin{tabular}{|c|c|c|c|}
\hline & Awareness & Decision to Enroll & Enrollment Process \\
\hline General & $\begin{array}{l}\text { Significant confusion and } \\
\text { very little understanding } \\
\text { about Medicaid and } \\
\text { private insurance } \\
\text { subsidies through the } \\
\text { Marketplace }\end{array}$ & $\begin{array}{l}\text { Unfavorable } \\
\text { attitudes toward the } \\
\text { individual mandate } \\
\text { - Significant mistrust } \\
\text { in the system }\end{array}$ & $\begin{array}{l}\text { - Complexity of materials } \\
\text { makes plan selection } \\
\text { difficult }\end{array}$ \\
\hline Messaging & $\begin{array}{l}\text { Messaging consumers } \\
\text { were hearing about } \\
\text { insurance was not } \\
\text { compelling and did not } \\
\text { discuss the health } \\
\text { benefits of insurance }\end{array}$ & $\begin{array}{l}\text { Messaging was not } \\
\text { often tailored or } \\
\text { actionable }\end{array}$ & $\begin{array}{l}\text { - Misinformation across } \\
\text { stakeholders }\end{array}$ \\
\hline Operational & $\begin{array}{l}\text { - Not enough funds or data } \\
\text { to support local outreach } \\
\text { and education }\end{array}$ & $\begin{array}{l}\text { - Health insurance } \\
\text { coverage is not } \\
\text { affordable }\end{array}$ & $\begin{array}{l}\text { Lag times and poor } \\
\text { communication about } \\
\text { eligibility-related decisions } \\
\text { - } \quad \text { Must apply for Medicaid } \\
\text { and be denied before } \\
\text { applying for private } \\
\text { insurance } \\
\text { - Connect for Health } \\
\text { Colorado website was not } \\
\text { user-friendly }\end{array}$ \\
\hline
\end{tabular}

\section{Awareness}

Our analysis identified three barriers related to awareness of insurance and coverage options: significant confusion and very little understanding about Medicaid and private insurance subsidies through the Marketplace, a belief that messaging about insurance was not compelling 
and did not discuss the health benefits of having insurance, and the lack of funds and data to support local outreach and education.

General Barrier: Significant Confusion and Very little Understanding About Medicaid and Private Insurance Subsidies Through the Marketplace

While individuals were aware of health insurance reform or health care coverage at a very high level, there was significant confusion and little understanding about eligibility, cost, and differences between health insurance options. For Medicaid, this included a lack of knowledge about expanded eligibility criteria, particularly for those who had been denied for Medicaid previously, or who had recently lost coverage.

People even in the city think that if you own home or car then you won't qualify for Medicaid, and that's not true. You don't have to be totally penniless. (Consumer)

I didn't even think I'd qualify. I had private insurance all my life, it was bad coverage. I didn't think I'd qualify for Medicaid because of my pre-existing condition. (Consumer)

In addition to challenges in understanding Medicaid, many individuals did not comprehend how to qualify for subsidies for private insurance or what level of income was needed to obtain a subsidy. According to stakeholders, consumers with higher incomes often assumed they would be ineligible for subsidies, particularly if they were currently employed.

Individuals not currently enrolled didn't realize Medicaid was free. They were also not aware of subsidies or how they worked. (Stakeholder)

There was also confusion about the difference between Medicaid and subsidized private insurance, particularly with respect to the coverage benefits of each.

It's not clear about what you receive from Medicaid versus Marketplace insurance. Need to do a better job of explaining what the difference between the two is and then more people will be on board. (Consumer)

Many people had heard from the media about health care coverage, but not a lot of details. Some of the benefits like preventive care and dental coverage were not known. (Consumer)

Finally, most participants did not know or think about the fact that they would have to reenroll in health care coverage annually. This is a significant barrier that must be addressed to ensure that the efforts to enroll individuals in this enrollment period do not result in loss of coverage in the next open enrollment season.

Messaging Barrier: Messaging Consumers were Hearing (e.g., from Media, Politicians, Stakeholers) About Insurance Was Not Compelling and Did Not Discuss the Health Benefits of Insurance

Both uninsured and newly insured individuals universally felt that the messaging to encourage health care coverage was off-target. They remarked that the messaging was almost always 
centered on insurance coverage, rather than health. Individuals stated that they were "not yet sold" on the overall importance of health insurance, and said that framing messages about how health insurance can help you to become and stay healthy would be compelling. Of note, nonemergency dental coverage for adults with Medicaid appeared to be the least well known and the most compelling health benefit, suggesting that messaging about dental benefits may be particularly effective. Some stakeholders suggested that on a statewide level, it may be beneficial to hire a marketing firm to help people understand the need for insurance with respect to improving health.

People want to hear the benefits about health insurance instead of the penalties.

People are not seeing how it will benefit them. (Consumer)

I think the messages need to be a lot more positive. This is coming from someone who eats out of food pantries and barely makes ends meet ... there Obama is on TV telling me I should pick health insurance over cable TV? So that's one more thing they're taking away from me. It's that "we're taking something away from you to get something I say you have to have" not "I'm taking something away from you because it's better for you." (Consumer)

Operational Barrier: Not Enough Funds or Data to Support Local Outreach and Education Several stakeholders at assistance sites reported that they did not receive enough funding to do direct media marketing to individual communities, which limited their ability to conduct localized outreach and education. Assistance sites used what funds they did have to conduct grassroots outreach activities, including presentations at local community-based organizations such as schools, chambers of commerce, faith based communities, homeless shelters, taxpreparation establishments, and libraries. Stakeholders also reported using health fairs to target potential enrollees; while some stakeholders had success in this venue, others found this method of outreach less effective than other approaches, given the lack of personalization and inability to follow-up with clients easily. For example, individuals who stopped at booths and collected materials about enrollment frequently left no personal information for follow-up communication.

Holding health fairs were not as useful for reaching people as creating partnerships with existing organizations that have a lot of uninsured people. (Stakeholder)

Many stakeholders reported that leveraging existing relationships with community-based organizations, including health care partners and local health practices was critical to outreach efforts. Assistance sites held educational events for office staff to educate them about Medicaid and eligibility for subsidies for private insurance that the staff could, in turn, share with their patients. Health care systems were also considered good avenues to reach the uninsured, since these locations offered a captive audience of individuals already engaging with the health care system. In some cases, assistance sites targeted individuals who had unpaid balances at associated clinics via phone or mail to enroll in Medicaid, $\mathrm{CHP}+$, or private insurance. In other cases, assistance sites reached out to clinic patients who participated in sliding scale fee 
programs. Although some assistance sites effectively used billing and demographic data to prioritize individuals for outreach efforts, stakeholders acknowledged that more data are needed. Data are also needed to help track the effectiveness of particular methods of outreach. For example, although many novel approaches were used for enrollment, it was not clear which methods resulted in the most success.

It [was] so hard to tell [which] methods were effective. . . . Would be nice to track how people make it to the door so that they can track effective outreach approaches. (Stakeholder)

Data is your friend. You can use data to help target people but also need data to help track results. (Stakeholder)

While assistance sites effectively leveraged existing partnerships, networks, and data, stakeholders noted that additional funds would have allowed for supplemental and more robust outreach efforts, including direct marketing or outreach to uninsured individuals who may not be as well connected to social services or other community organizations.

\section{Decision to Enroll}

Our analysis identified four barriers related to the decision to enroll: unfavorable attitudes toward the individual mandate, significant mistrust in the system, the perception that messaging was neither tailored nor actionable, and the belief that health insurance coverage is not affordable.

General Barrier: Unfavorable Attitudes Toward the Individual Mandate

Many of the participants in our focus groups were aware of the individual mandate - the requirement that individuals have health care coverage or pay a fine (i.e., 1 percent of annual household income or $\$ 95$ flat rate for a single adult with a household income of less than $\$ 19,650$ ) - through various messaging platforms, such as radio or television. However, they noted that there were very few positive messages and that much of the information surrounding health insurance coverage from the media and politicians was negative, politicized, and framed in a threatening way. Most participants referred to the mandate as "Obamacare," often associating it with politics rather than the need for care. Consumers did not like the idea of the federal government mandating insurance purchase. Given that the ACA continues to be hotly debated within the United States, some individuals revealed that they did not enroll because they assume it will be repealed; others did not want to be associated with the policy.

It is political, it's not about health. I noticed that there is a lot of perception that health care is not really for the patient, so people don't want to bother with it, even if it is affordable. (Consumer)

People are blaming Obama, so people feel that getting health care is supporting Obama. (Consumer) 


\section{General Barrier: Significant Mistrust in the System}

There was also a lot of mistrust expressed among the uninsured. This included mistrust of the government and other key players, including health insurance companies. Consumers noted that the lack of transparency in the process, coupled with complexity of information, materials, and processes that do not clearly convey relevant information, such as costs and coverage, significantly contributed to their mistrust. Some consumers felt that insurance companies were intentionally being deceptive by using complex language to conceal hidden fees. Others felt that "Obamacare" was a political agenda to obtain individuals' personal information and an invasion of privacy. Stakeholders agreed that these sentiments were barriers to enrollment and that many consumers were not interested in having a conversation about health care coverage because of this high level of mistrust. For those consumers willing to have a conversation, stakeholders reported having to spend significant time to address consumers' fears about government intrusion.

Information on the Internet is inconsistent and not accurate. My wife spent hours researching and talking to people about it. She would talk to one person one day and heard one thing, and then the next day talk to another person and hear another thing. We decided to withdraw because (1) It's from the government, (2) it's intimidating, (3) it's grossly mishandled, and (4) there is no basis for the government to be involved in health insurance. (Consumer)

I heard that the information they gave me is biased and I was told that Medicaid is now scrutinizing your checking account because of Obamacare, so I didn't want that. I'm not sure if that is true or not. (Consumer)

To overcome these negative perceptions, stakeholders relied on trusted, known leaders within the community to help with outreach to communities. This was particularly important for areas and groups that were traditionally harder to reach. For example, in a rural area that had high levels of mistrust of the government and the expansion efforts, one stakeholder used a local leader to go to homes to relay the message about coverage. In another case, an assistance site worked with a trusted professor who presented information about insurance enrollment to college students. The assistance site was able to partner with the campus union to enroll students following the presentation.

In areas where there was a general community sentiment to avoid using government services, presentations held in public venues were not well attended. In these cases, meeting in a private space, such as a home or closed space in a library, was preferred. Most stakeholders reported that while initial contact was often with established clients who used other services at their organization or agency, the best source of referral was word of mouth. Friends or family members would refer potential clients for enrollment, particularly after having a positive experience. Consumers stated that word of mouth was particularly effective as well. 


\section{Messaging Barrier: Messaging Was Not Often Tailored or Actionable}

Stakeholders reported that the majority of outreach and messaging that reached consumers was initiated by the central Connect for Health Colorado offices. As a result, individuals and stakeholders alike felt that in many cases the messages designed to facilitate decisionmaking about enrollment were not tailored to the local community and were not culturally responsive. For example, consumers in rural areas (i.e., Sterling, Colorado) reported viewing ads that showed young adults skateboarding and skiing; these messages made some consumers feel that health insurance was not necessary for their rural lifestyle.

[Connect for Health Colorado] should work with communities to help tailor [messages] to be more culturally appropriate. (Stakeholder)

Individuals also felt that the messages they did receive were not actionable. In other words, there were few concrete steps for individuals to follow who wanted to enroll and obtain specific information about where to go to get help with enrollment. This placed an added burden on individuals, which can be a significant barrier to enrollment, particularly if the individual has little time, no access to the Internet, or low literacy skills, which may impede an individual's ability to navigate the system to find the relevant information.

The majority of people aren't going to get health insurance because they don't know how to proceed. (Consumer)

If you are not already affiliated with a clinic or social service organization, it is not clear where to go to enroll. (Stakeholder)

\section{Operational Barrier: Health Care Coverage Is Not Affordable}

The cost of insurance was perhaps one of the biggest barriers reported by the uninsured. While we anticipated this being discussed in the Colorado Mountain Resort region, given that this region had the highest premiums in the nation (Kaiser Health News, February 3, 2014), the sentiment that insurance was simply not affordable was universal. While some of this perception may be driven by a lack of understanding about the availability or eligibility for subsidized private insurance, most individuals were citing co-pays, deductibles, and other out-of-pocket expenses that they would be responsible for beyond the cost of their monthly premium, suggesting that this is not simply a barrier that may be addressed with clearer messaging. The concern about cost was especially true among individuals who did not meet eligibility for Medicaid.

Sometimes I feel penalized for not being at the bare bottom. I barely keep my head above water, I have a master's degree and I can't afford life. When you're in the middle you're stuck. (Consumer)

My husband doesn't have insurance. He can't afford it through his job, yet he doesn't quality for other options. It will cost him his entire paycheck to cover our family of four and we can't have that. My mom's freaking out, she's not covered and she can't afford it either. (Consumer) 
The uninsured also pointed to the availability of free or charitable care that was seen as "a better deal" than health insurance coverage through Medicaid or private insurance through the Marketplace. Not only was it viewed as less expensive, but it was also perceived as more straightforward. In one region, because the sliding scale fee structure was so low, some individuals preferred to stay uninsured with the existing flexible payment program rather than choose a higher cost of enrollment.

Personally I am anti-insurance. ... Even when you go for insurance you still get a bill one or two months later for 80 or 100 dollars. . . Not having insurance is simpler, you pay once and it's a done deal. (Consumer)

\section{Enrollment Process}

Our analysis identified five barriers to the enrollment process: the complexity of materials, which makes plan selection difficult, misinformation across stakeholders, lag times and poor communication about eligibility-related decisions, the requirement that individuals apply for Medicaid and be denied before applying for private insurance, and challenges with the Connect for Health Colorado website.

\section{General Barrier: Complexity of Materials Makes Plan Selection Difficult}

Some individuals reported that the complexity of the materials and, in some cases, the sheer volume of plan choices made selecting a plan particularly challenging. Though the goal is to increase the number of individuals who have health insurance coverage, if they do not understand their choices or select a plan that does not really meet their needs and budget, they may be less satisfied and run the risk that they will choose not to re-enroll next year. Both consumers and stakeholders agreed that consumers, especially those with complex circumstances or with low health literacy, needed individual help to navigate the system for enrollment.

There is a wide fluctuation in price from $\$ 3$ to $\$ 85$ a month and I didn't know how to distinguish. I fell back on Medicaid because I didn't know how to compare. ${ }^{6}$ (Consumer)

I wanted to talk to somebody, even if was to make sure all the bases are covered. I want to make sure I was getting the best deal. I have a family of four and I have different needs than the rest of my family. You need to make sure you get the right coverage and know what it entails. It shouldn't be an automated response. (Consumer)

\footnotetext{
${ }^{6}$ Eligibility for Medicaid or subsidized private insurance is dependent on income; individuals cannot "fall back" on Medicaid if they do not understand subsidized health plans. Because Medicaid eligibility is based on monthly income, it may be possible for an individual to be eligible for subsidized private insurance one month, but have a subsequent reduction in monthly income such that they become eligible for Medicaid at a later date. While the exact situation of this consumer was not probed during the focus group, the quote further highlights the confusion many consumers have with respect to health insurance and the difference between Medicaid and subsidized private insurance.
} 


\section{Messaging Barrier: Misinformation Across Stakeholders}

It is not surprising that individuals turn to a wide range of resources and stakeholders within the community to get information and assistance with health insurance questions. One challenge with this, however, is that the knowledge base of these stakeholders and the accuracy in the information and advice given varies significantly. While some had positive experiences and received helpful information, others found out after the fact that the information they had been provided was incorrect. This conflicting information within the community can serve as a barrier to enrollment and feeds the mistrust of the process discussed earlier in this chapter.

A health coordinator for Medicaid called me. I got confused about my son's eligibility so I called her. She's local. I just call her and she was able to help me with eligibility questions. (Consumer)

My case manager didn't even know. They'll tell you that as an adult you can't apply for Medicaid because you don't have kids. (Consumer)

Stakeholders, on the other hand, noted that much of the misunderstanding and misinformation was due to a lack of marketing and information sharing about Medicaid eligibility. Stakeholders with whom we spoke said that many people (consumers and local stakeholders alike) did not understand that Medicaid enrollment could occur at any time and was not tied to the open enrollment period for Marketplace plans. Stakeholders also stated that it was often hard to distinguish between Medicaid and Marketplace enrollment through the existing statewide media campaigns.

[We] need to educate people that Medicaid enrollment is possible even after open enrollment is ended. (Stakeholder)

\section{Operational Barrier: Lag Times and Poor Communication About Eligibility-Related Decisions}

Individuals and stakeholders both noted that in some cases there was significant lag time between completion of the enrollment paperwork and notification about Medicaid eligibility. This is not only problematic for those who qualify for Medicaid, in that it delays access to coverage, but it also becomes particularly challenging with Colorado's two-stage enrollment process, as those who do not qualify are not able to proceed with enrollment in private insurance (see below for more information on this process). It is important to note that not everyone reported such lag times; in some cases, eligibility determination went very fast, suggesting the need for more standardization in training and procedures across enrollment assistance sites, or an examination of the Medicaid-eligibility determination process to streamline the process.

Stakeholders noted the importance of follow-up to help residents cope with enrollment lag times.

I can say that I was on Medicaid for over a year and then heard I didn't have coverage and then found out I had coverage all along. (Consumer)

It helped that the health guide every week could follow-up with their clients. So they would also call to find out status and then health guide could investigate to finish the case. (Stakeholder) 
One assistance site reported that lag times decreased when they started using the MoveIt secure email system, which allowed assistance sites to send the state contractor an email with attachments for documentation, all securely. This greatly facilitated the enrollment process and helped when guides needed a case reevaluated because of a Medicaid denial. It also assisted in processing Connect for Health Colorado subsidy applications. While many assistance sites did not use this system, it may be worth exploring other feasible options for the secure, electronic transfer of sensitive information given the potential for reducing lag times and better tracking and communication.

MoveIt helped significantly with facilitating enrollment. Before we had this account, we had many more barriers. (Stakeholder)

\section{Operational Barrier: Must Apply for Medicaid and Be Denied Before Applying for Private Insurance}

One of the more unique features of health insurance enrollment in Colorado is that individuals must apply for - and be denied - for Medicaid before being allowed to continue to purchase private health insurance through the Marketplace. This process was particularly problematic for this open enrollment period because the decision was made to change to the two-stage enrollment process just days before the start of the first open enrollment season. As a result, all the training, information, and procedures that assisters and other community stakeholders had learned was no longer relevant. This likely contributed to much of the inconsistent messaging described earlier in this chapter and caused the enrollment process to take longer-not only were the processes unfamiliar to those responsible for navigating it, but individuals had to apply for Medicaid, wait for an approval (or not), and then start the application process all over again for private insurance. As noted in some of the appendixes, this process was a major barrier for those who did not view government assistance as favorable and did not want to apply for Medicaid. Though we anticipate that some of the earlier glitches and confusion about this two-stage process will be resolved for the next open enrollment season, many barriers related to this process remain.

With the whole Connect for Health Colorado thing, the confusion is that you get there and it said you have to do Medicaid. If you didn't know you had to qualify for Medicaid first it was too time consuming. (Consumer)

\section{Operational Barrier: Connect for Health Colorado Website Was Not User-Friendly}

Individuals discussed a number of challenges with the Connect for Health Colorado website and support services, including constant busy signals for designated phone lines or not having phone messages returned by Connect for Health Colorado service agents. In addition, some consumers struggled with website navigation and were often unaware or unable to find regional assistance sites listed on the Connect for Health Colorado website to help with enrollment. These structural challenges led to a number of consumers who were initially ambivalent about obtaining health care coverage to choose to completely forgo coverage this year. 
I would get to a certain point and needed more information, I put in my contact information and was never called back. ... This happened 30 times. I can answer all the questions, but there are hiccups where you can't get further and the website is not user-friendly. The last time I tried was in February and I'm still waiting for a call back. (Consumer)

It was very confusing because I tried to enter the Internet and do it, and it would take me out and send me to another page, and it didn't have the answer. I needed to find someone who would help me and who would take away my doubts about this because I am not an expert-I don't know how this works. (Spanishspeaking consumer) 


\section{Special Populations}

In addition to the more universal barriers to health insurance coverage identified across Colorado (Chapter Two) and region-specific barriers outlined in Appendixes A-H, one of the objectives of this study was to identify unique barriers or challenges specific to special populations. Though additional information and detail on these populations and barriers can be found in the appendixes, we summarize some of the key findings here.

\section{Spanish-Speaking Populations and Families of Mixed Immigration Status}

Latino populations are lagging behind the rest of the country in Medicaid and private insurance enrollment through the Marketplace (Shartzer, Kenney, Long, Hempstead, \& Wissoker, 2014). Conversations with Latinos, and in particular those living in a household of mixed immigration status (mixed-status families) highlighted a number of barriers.

- There was confusion about what documentation was actually required to establish eligibility with respect to residence and citizenship requirements.

- Given that many individuals lived in mixed-status families, in which one or more members were not eligible for health insurance coverage under provisions in the ACA, the requirement of providing required documentation (e.g., proof of identity and lawful presence, proof of address, proof of household income) discouraged some Latino consumers in Colorado from seeking insurance coverage. This variability required extensive counseling and navigation efforts by the assistance sites.

- Consumers also noted a lack of culturally competent and bilingual staff to assist them with enrollment and to provide culturally and linguistically responsive care once enrolled.

- There was a lack of health insurance related messaging in ethnic media. As a result, Spanish-speaking populations in some regions felt less informed.

\section{Young Adults}

Young adults between the ages of 19 and $29,{ }^{7}$ often referred to as "young invincibles," have the highest uninsurance rate in Colorado and across the nation and also represent an enrollment challenge (Colorado Trust, 2013). Our interviews and focus groups demonstrated that it was particularly challenging to enroll younger individuals in insurance, for a number of reasons:

- There was (and continues to be) a perceived lack of need for insurance because these young adults generally feel healthy and do not consider themselves at risk for major chronic conditions.

\footnotetext{
${ }^{7}$ Connect for Health Colorado defines this population as individuals between the ages of 19 and 34.
} 
- Many younger residents tend to have part-time jobs and are therefore less likely to be eligible for employer-based coverage. Even with subsidies, cost barriers can be prohibitive for this population.

- Many younger people are also still covered under their parents' health plans, but they are not well supported when they look for insurance on their own for the first time. The complexity of the enrollment process and multitude of plan choices was often overwhelming for the youngest consumers.

- Traditional modes of dissemination may not reach this population, making it less likely that they will come in contact with key messages. While television, radio, and print may be effective for older consumers, younger consumers noted that they are more likely to utilize social media and to stream their entertainment on demand (e.g., through Netflix or Pandora).

\section{Rural Populations}

Rural populations are, not surprisingly, harder to reach and enroll in health insurance. Apart from the logistics of reaching fewer individuals over a much larger geographic region, a number of other barriers were identified:

- Mistrust of health insurance reform seems to be higher in rural areas of Colorado. The anti-government sentiment was particularly high in areas that were more conservativeleaning, and such mistrust was a significant barrier to health insurance enrollment in some of these communities.

- The messaging and state-sponsored marketing was not necessarily specific to rural populations; many of the media campaigns were targeted toward the larger cities. Those messages that were transmitted were considered to be crafted for larger, more liberal metropolitan areas rather than being tailored to more conservative rural areas. As a result, the messaging did not resonate.

- Some of the rural areas in the western part of the state access television stations and other media from neighboring New Mexico, rather than Colorado, and as a result did not get as much exposure to ads for the Colorado marketplace.

- Rural areas also have fewer health care providers. This is important because not all providers take Medicaid, and there is a concern that by enrolling in health insurance coverage, individuals will have to change providers or will have to go to a provider who is much further away.

- Internet connectivity is expensive and not readily available. Because of this, information disseminated primarily through the Connect for Health Colorado website is not reaching consumers in more rural areas, and online enrollment processes are also not realistic options for these consumers, who will need phone-based or in-person enrollment assistance. 


\section{Seasonal Workers}

Many of the seasonal workers who participated in our focus groups were primarily Spanishspeaking, and as a result experienced many of the barriers noted above. In addition, seasonal workers faced several additional barriers:

- Seasonal workers often rotated on and off insurance or across insurance types depending on their current employment status. This requires a significant time investment and is often confusing. In some cases, it ended up costing the individual more money out of pocket, as the deductible limit was reset with each enrollment into a new insurance plan.

- Because enrollment in Medicaid and subsidized private insurance is dependent on income, filling out enrollment applications is difficult for many seasonal workers, who have earnings for only part of the year. Medicaid bases eligibility on monthly income, while subsidies for private insurance are calculated based on annual income. Therefore, seasonal workers may be eligible (or not) for different insurance coverage options depending on when they are filling out the paperwork.

- Many seasonal workers reside in resort towns, where health insurance is even more expensive, placing an added burden on this population.

- Seasonal workers also include young adults, who are relatively healthy (see barriers related to the "young invincibles," above) and do not see the need for health insurance.

The findings above highlight special considerations for strengthening outreach and enrollment efforts for these populations. Additional context and detail related to these populations can be found throughout Appendixes A-H. 


\section{Recommendations and Conclusions}

This project sought to understand why individuals were not enrolling in health insurance in Colorado. To accomplish this, we spoke with a wide array of individuals - both uninsured and newly insured individuals - as well as community stakeholders across the state. These interviews and focus groups revealed a number of barriers, and, in most cases, challenges arose when there was a disconnect between (1) what was being provided to consumers in terms of messaging, processes, and infrastructure and (2) the needs and abilities of consumers to understand health care coverage and to find, access, and navigate resources to help them with enrollment and decisionmaking.

In this chapter, we provide a series of recommendations to address the identified barriers, regarding those that rise to the top as higher priority based on the study findings. It should be noted that given the lag time between our data collection efforts in late July 2014 and the release of this report, Connect for Health Colorado or other stakeholders within Colorado may have already begun to address one or more of these barriers.

The recommendations below are not written with a specific stakeholder group in mind. Rather, fully addressing these barriers will likely require a collaborative approach of time, energy, expertise, and resources. These recommendations are also not intended to be overly prescriptive, but are meant to generate discussion among community stakeholders and serve as a catalyst for the development of focused solutions at the local, regional or state level.

\section{Recommendations}

Though we present the barriers in Chapter Two (and again in Appendixes A-H) to align with the stages of our conceptual framework (i.e., awareness, decision to enroll, enrollment process), we perceive many of these barriers to be related. Table 4.1 reorganizes these barriers to illustrate how they cluster and provides potential recommendations for addressing these barriers. Each recommendation is discussed in more detail below. 
Table 4.1. Recommendations to Address Enrollment Barriers

\begin{tabular}{lll}
\hline \multicolumn{1}{c}{ Barrier } & \multicolumn{1}{c}{ Recommendation } \\
\hline - $\begin{array}{l}\text { Not enough funds or data to support local } \\
\text { outreach }\end{array}$ & - $\begin{array}{l}\text { Support and expand localized outreach and tailored } \\
\text { messaging }\end{array}$ \\
$\begin{array}{l}\text { Messaging was often not tailored or } \\
\text { actionable }\end{array}$ & \\
\hline - $\begin{array}{l}\text { Confusion about Medicaid and private } \\
\text { insurance subsidies }\end{array}$ & $\begin{array}{l}\text { Strengthen marketing and messaging to be (1) clear, (2) } \\
\text { actionable, and (3) focused on the health benefits of } \\
\text { insurance (to overcome negative or politicized messaging } \\
\text { from the media) }\end{array}$ \\
- Messaging about insurance was not \\
$\begin{array}{l}\text { compelling and did not discuss the health } \\
\text { benefits of insurance }\end{array}$
\end{tabular}

\section{Support and Expand Localized Outreach and Tailored Messaging}

Several assistance sites reported that they did not have adequate funds to support robust outreach efforts to their local constituents. This sentiment was supported by consumers who reported that they did not knowing where or how to seek assistance with enrollment in their communitysome consumers were not able to identify local resources even after a targeted Internet search. Funds to help assistance sites expand their capacity for local advertising and outreach, as well as improvements in messaging and Service Center referrals and support, may help bridge this gap.

Consumers also expressed a desire for assistance sites to increase the availability of one-onone counseling and expand capacity to provide such services. It is not clear whether this perception of need was due to a lack of knowledge about available resources in the community (i.e., one-on-one assistance is available but consumers don't know about it) or due to the workload of assistance sites (i.e., consumers connected with assistance sites but were not able to receive individualized assistance). It may be worth examining current and projected workload capacity and staffing needs for the upcoming open enrollment season in light of potential improvements to the enrollment process and to outreach and messaging that may connect more consumers with local enrollment assistance sites.

Although additional financial provisions from Connect for Health Colorado or other agencies to support outreach will likely strengthen outreach efforts, assistance sites may also benefit from an expansion and strengthening of community partnerships and referral networks. During the 
first open enrollment season, many assistance sites focused their efforts on easier-to-reach populations - individuals already connected to health care or social services being provided by partner organizations. Efforts to support additional linkages across expected and nontraditional community stakeholders, such as online streaming services, libraries, post offices, and small business employers, will enhance the outreach and referral process. These partnerships will be particularly important as the uninsured become harder to reach. New partnerships can also become important dissemination channels of messaging more generally, as trusted messengers of these organizations may be able to reach more marginalized populations. More information may be needed to better understand the specific financial, training, or technical assistance needs of communities to support the growth and effectiveness of such linkages.

Strengthening local outreach efforts also provides an opportunity for the development of tailored messaging. While messages may be tailored naturally for localized outreach, assistance sites should be strongly encouraged to develop tailored messages and approaches to ensure that they meet the needs of the unique populations they serve. Such efforts should ensure that messages, messengers, and approaches for dissemination address contextual issues (e.g., rural, seasonal worker) as well as the cultural and linguistic preferences of consumers.

\section{Strengthen Marketing and Messaging to Be (1) Clear, (2) Actionable, and (3) Focused on the Health Benefits of insurance (to Overcome Negative or Politicized Messaging from the Media)}

A number of barriers identified through this project suggested that the specific messages about health insurance options and enrollment processes were often unclear and not compelling, suggesting that the marketing strategy and messages may need to be revisited.

First, there is an immediate need to clarify and simplify messaging about health insurance options. While consumers had heard about health care reform, they lacked a fundamental understanding of what it was and what it meant for them. All messaging should be reviewed for clarity of message and literacy level (5th grade or below).

Second, messages should be strengthened to be more actionable so that consumers know exactly what to do or where to go to get assistance with enrollment in health care coverage. The level of specificity is important. It is not enough to say "see your local assistance site for more information"; instead messaging should be tailored to provide names, locations, and contact information for local assistance sites. This may be a potential role for regional hubs, which could customize core messages from Connect for Health Colorado with local information and disseminate them on behalf of assistance sites in their region.

Third, messaging should focus on the health benefits of insurance, to help overcome messages that consumers tend to remember related to politics or financial penalties. Most consumers felt that the messaging they heard through the media and other sources about health insurance was negative and threatening. They felt a more specific discussion about the health 
benefits of insurance, such as coverage for immunizations free visits for preventive care and dental coverage, would be useful and compelling.

These recommendations will not only help consumers who are looking to enroll in health insurance, but will also facilitate community stakeholders' understanding of the nuances of health insurance and enrollment. This shared understanding by stakeholders will help guarantee the consistency and accuracy of messages that are being given to the consumer. Such messages may be disseminated through existing (and future) community networks and partnerships to ensure that this information is reaching a wide range of stakeholders.

\section{Improve the Clarity and Transparency of Insurance and Health Care Costs and Enrollment Procedures}

Though improving localized outreach efforts and strengthening messaging about health insurance is likely to have a measurable impact on enrollment, it is also important to acknowledge that there was a strong underlying current of mistrust among many of the uninsured focus group participants. In many cases, individuals were associating health insurance with a political agenda they did not support and a process they did not understand, and they were wary of signing up for something that was going to cost them unspecified amounts of money in the future. While some of this mistrust may be addressed by reframing messages, as described above, this mistrust is difficult to address because it is closely tied to politics, health care financing, and personal values and beliefs, all of which are very difficult to change.

Policymakers and health insurance companies alike should consider options for alleviating cost barriers or improving transparency about total out-of-pocket costs for each plan. Consumers, for example, wanted health insurance options explained in dollars and cents, rather than a percentage of coverage. Percentages are not only harder to calculate, but the total cost of these services varies by provider and is not transparent. For individuals on tight budgets, this quickly becomes a risk they are not willing to take. Though we acknowledge the inherent challenge in this proposed strategy, given the current financing and pricing structures of health care, the reality is that many individuals were forgoing health insurance and instead continuing to receive care at locations with free or sliding fee scales because they knew in advance exactly how much their visit would cost. Successfully addressing this barrier will require more than transparency, however, as lack of affordable insurance was consistently viewed as a challenge, even in areas that have recently lowered premiums.

Trust in outreach and enrollment efforts is also being undermined by fraudulent websites and activities. Many consumers reported not being able to tell what was and what was not an official enrollment website. Stakeholders in Colorado should monitor for and seek to disable fraudulent websites, or consider the development of a widely recognized icon or branding mechanism to help the consumer discern real vs. fraudulent encounters. Improving the transparency of the enrollment process may also help rebuild consumer trust. Many consumers, for example, did not 
know about the two-stage enrollment process when their intent was to apply for private insurance.

\section{Revisit the Two-Stage Enrollment Process and Improve Connect for Health Colorado Website Navigation and Technical Support}

During the first open enrollment season, individuals in Colorado interested in enrolling in private health insurance through the Marketplace had to first apply for Medicaid. In many cases, consumers were eligible for Medicaid and enrolled, and in these cases this two-stage process had little impact on the consumer experience. For individuals who were looking to enroll in subsidized private insurance, however, this process was viewed as onerous, particularly for those not interested in government assistance (e.g., due to stigma) or who knew they were not eligible for Medicaid. Consumers reported that the Medicaid enrollment process took 2-3 hours on the phone and included questions about other social service programs. Not only was this considered excessive, invasive, and not a good use of consumer time, it also sends a negative message to consumers that their time and personal preferences are not valued, further contributing to the perception of mistrust of the system. These findings suggest a need to revisit this process, perhaps allowing interested consumers to bypass the Medicaid-eligibility determination step should they choose, or replacing the full Medicaid enrollment process with a very quick screener to allow those who are clearly not eligible to receive that determination within minutes.

Streamlining this process is also likely to have a positive impact on the lag times and poor communication about eligibility and approvals to move forward with the selection of private insurance that some consumers experienced. Regardless of whether modifications can be made to this two-stage process, Medicaid and Connect for Health Colorado should also examine inconsistencies in consumer experience with the enrollment process itself. Some felt the process was easy, whereas others experienced significant frustration with staff who could not answer questions or help the consumer address a concern. This wide variability suggests a need for stronger and more consistent training, quality assurance, and customer service accountability.

\section{Summing Up}

This report synthesized findings from our interviews and focus groups with local stakeholders and uninsured or recently insured consumers through Medicaid or subsidized private insurance across the state of Colorado. We did not examine barriers among consumers who were eligible for employer-sponsored insurance, nor did we examine the particular health care experiences or challenges faced by individuals who were not eligible for coverage under the ACA (e.g., due to immigration status). It should be noted that we did not seek to enroll a representative sample for a given region, or for the state overall. Rather, we spoke to a limited number of individuals within a given city in that region, and in many cases recruited special populations (e.g., parents, young adults, racial or ethnic minorities). While this design had advantages in that we were able 
to ensure feedback from a diverse mix of regions and special populations across Colorado, we acknowledge the findings from any one focus group may not be fully generalizable to the rest of the region and may not capture all of the barriers experienced by consumers in that region. We also did not speak to individuals from the San Luis Valley region, and as a result specific barriers for that region were not captured and are not reflected in this report. It should be noted that in most cases, consumers who participated were self-selected in that they responded to a notice about the study. As a result, the findings may not be representative of all uninsured and recently insured individuals across Colorado; those who were able to enroll with little difficulty may have been less likely to participate, for example. Similarly, we spoke to a limited number of stakeholders responsible for outreach and enrollment, and, as a result, the findings may not be generalizable or reflect the experiences of others tasked with outreach and enrollment. However, these interviews provided important contextual information, and findings were, for the most part, consistent with what we heard from consumers.

Despite these limitations, findings about barriers to enrollment across focus groups and interviews were quite consistent. While there was some regional variability, particularly with respect to relative emphasis of these barriers, uninsured and newly insured Coloradans were struggling with similar issues. The recommendations above are intended to stimulate creative and tailored local solutions that will support an increased understanding of the value health insurance, the decision to enroll, and improvements in the enrollment process for uninsured individuals in Colorado. Ongoing evaluation and monitoring of these efforts may be warranted to document the impact of such changes, to identify lessons learned, and to further refine these recommendations moving forward. 


\section{Appendix A. Barriers to Health Insurance Coverage-Metro Region}

\section{Overview}

The Metro Region includes the following counties: Adams, Arapahoe, Broomfield, Denver, Douglas, and Jefferson. Though Boulder is often listed as part of the Metro region, for the purpose of this study we include it as part of the North Central region (Appendix B). We held three focus groups in this area (highlighted with black dots on Figure A.1) with a total of 41 participants. One focus group was conducted in Spanish, and one group had a high representation of African American participants. Just over 70 percent of participants were female, and participants were between the ages of 18 and 61, with a median age of 41 . About 63 percent were Latino, 42 percent were married, and 51 percent had at least one child. Three focus groups were held in this region.

The Denver Metro Area Region contains more than half the state's population, with more than 2.9 million residents (U.S. Census Bureau, 2013). Racial/ethnic minorities represent onethird of the total population in this region (22 percent Hispanic origin; 5 percent African American; 4 percent Asian) (U.S. Census Bureau, 2013). Among the Metro population age 0-64, approximately 9.2 percent were Medicaid- or CHP+-eligible but not enrolled, and 6.7 percent qualified for tax credits in 2012 (Colorado Health Institute, 2014a). The Metro region had 42 percent of consumers who qualified for tax credits enroll in private insurance through the Marketplace (52 percent of the total number of Marketplace enrollments) and 41 percent of eligible consumers enroll in Medicaid (Colorado Department of Health Care Policy and Financing, April 2014a; Colorado Health Institute, 2014a). 
Figure A.1. Metro Region of Colorado and Location of Focus Groups (Denver, Colorado)

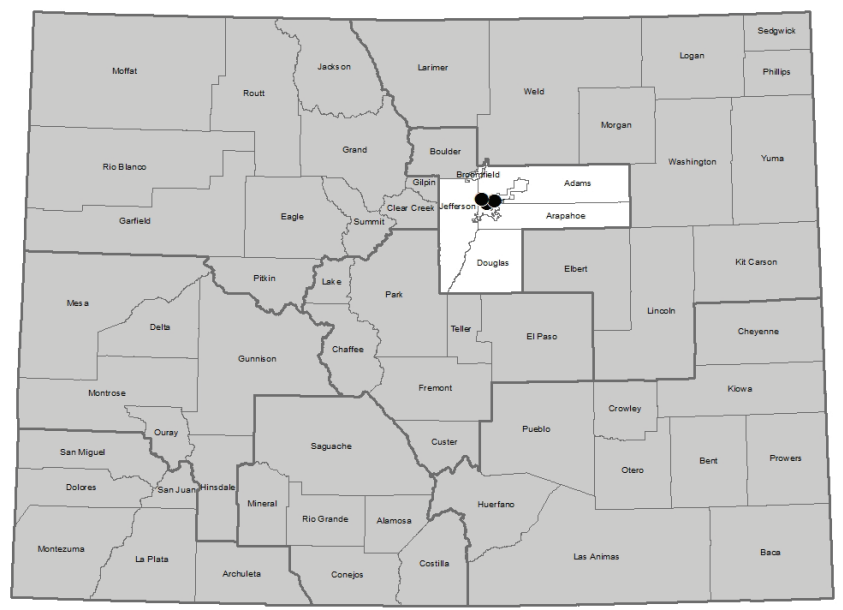

Of the barriers identified in Chapter Two, the following were discussed most often by consumers in the Metro region:

- Significant confusion and very little understanding about Medicaid and private insurance subsidies through the Marketplace

- Messaging about insurance was not compelling and did not discuss the health benefits of insurance

- Significant mistrust in the system

- Messaging was not often tailored or actionable

- Health insurance coverage is not affordable

- Lag times and poor communication about eligibility-related decisions

- Must apply for Medicaid and be denied before applying for private insurance

- Significant lag times between application processing and approval notices.

One additional barrier reported by consumers in this region related to negative past experiences with Medicaid. Three additional barriers were reported by the Latino population: challenges verifying eligibility, concern about engaging the system particularly for families with mixed insurance eligibility, and lack of culturally competent staff to assist with enrollment. 
Table A.1. Barriers to Health Insurance Coverage in the Metro Region

\begin{tabular}{|c|c|c|c|}
\hline & Awareness & Decision to Enroll & Enrollment Process \\
\hline General & $\begin{array}{l}\text { Significant } \\
\text { confusion and very } \\
\text { little understanding } \\
\text { about Medicaid and } \\
\text { private insurance } \\
\text { subsidies through } \\
\text { the Marketplace }\end{array}$ & $\begin{array}{l}\text { - Unfavorable attitudes } \\
\text { toward the individual } \\
\text { mandate } \\
\text { - Significant mistrust in the } \\
\text { system } \\
\text { - Negative past } \\
\text { experience with } \\
\text { Medicaid } \\
\text { Concern about engaging } \\
\text { the system for mixed- } \\
\text { eligibility families }\end{array}$ & $\begin{array}{l}\text { - Complexity of materials } \\
\text { makes plan selection } \\
\text { difficult } \\
\text { - Challenges verifying } \\
\text { eligibility } \\
\text { - Lack of culturally } \\
\text { competent staff }\end{array}$ \\
\hline Messaging & $\begin{array}{l}\text { Messaging } \\
\text { consumers were } \\
\text { hearing about } \\
\text { insurance was not } \\
\text { compelling and did } \\
\text { not discuss the } \\
\text { health benefits of } \\
\text { insurance }\end{array}$ & $\begin{array}{l}\text { Messaging was not often } \\
\text { tailored or actionable }\end{array}$ & $\begin{array}{l}\text { - Misinformation across } \\
\text { stakeholders }\end{array}$ \\
\hline Operational & $\begin{array}{l}\text { Not enough funds } \\
\text { or data to support } \\
\text { local outreach and } \\
\text { education }\end{array}$ & $\begin{array}{l}\text { - Health insurance coverage } \\
\text { is not affordable }\end{array}$ & $\begin{array}{l}\text { - Lag times and poor } \\
\text { communication about } \\
\text { eligibility-related decisions } \\
\text { - } \text { Must apply for Medicaid } \\
\text { and be denied before } \\
\text { applying for private } \\
\text { insurance } \\
\text { Connect for Health } \\
\text { Colorado website was not } \\
\text { user-friendly }\end{array}$ \\
\hline
\end{tabular}

NOTE: Bold font indicates region-specific barriers not discussed in Chapter Two.

\section{Regional Barriers}

\section{Negative Past Experiences with Medicaid}

Focus group participants recounted negative interactions with the health care system through prior experiences with Medicaid in Colorado. Individuals who had previously been covered by Medicaid cited a lack of providers accepting Medicaid (especially specialists), the inability to schedule doctor appointments in a timely manner among providers who were accepting Medicaid, and feelings of getting second-rate health care while on Medicaid. Consumers who were eligible for but not enrolled in Medicaid cited these experiences as reasons for choosing not to enroll in health care coverage in Colorado.

I spent two months trying to find a doctor. Either got "we don't accept [Medicaid]" or that "we accept [Medicaid] but have no appointments available". (Consumer)

My grandparents had Medicaid. Folks kept sending them from doctor to doctor to doctor; you get the runaround, and it doesn't cover everything. (Consumer) 
At my age (50s), I don't like to show Medicaid card because then they [doctors, health care staff] treat you differently, like you're lower than the others or something. (Consumer)

\section{Barriers for Spanish-Speaking Latinos}

\section{Challenges Verifying Eligibility}

Spanish-speaking Latino consumers discussed challenges with health insurance enrollment because of the requisites and documentation needed to verify eligibility, particularly regarding citizenship or immigration status. These requirements often led to confusion about the process, which may have been exacerbated by consumers not knowing where to go for Spanish-language assistance.

But as long as you don't have a good social security number you can't get insurance. But my husband got a letter from that said everyone needed to have health insurance. And so our question is yes or no - can it be done or not? (Spanish-speaking Consumer)

There was a lot of confusion, it was really confusing - where to go, what to do, how to do something. For example, before I couldn't buy [health insurance] and then I heard about Obamacare, and then I was fascinated, "oh Obamacare! It's going to help me." But then when someone sees the points, point \#1, the bronze, point \#2 the gold. In each one, you see the price and depending on your income, a person comes out paying way more than what one was picturing that it was going to be beneficial for them. To me it did seem a little bit complicated. (Spanish-speaking consumer)

\section{Concern About Engaging the System for Mixed Immigration Status Families}

Lawfully present immigrants who have been in the United States for less than five years are not eligible for Medicaid, but may enroll in private insurance; they are also subject to the individual mandate. (National Immigration Law Center, 2014). This posed a challenge for many Spanishspeaking Latino families in which some, but not all, family members were enrolled in health insurance coverage. This could occur, for example if one spouse has been in the United States for more than five years, and the other for less than five years; or if the husband received insurance through his employer, the children through $\mathrm{CHP}+$, and the wife has been lawfully present for less than five years. In these cases, many families could not afford private health insurance for the one or more members who were not eligible for Medicaid and were resigned to have to pay the penalty. Consumers also noted that some Latino college students were choosing lower-income employment in order to maintain Medicaid eligibility, especially if they were not eligible for their parents' insurance due to the parents' immigration status.

My husband did get Medicaid but I didn't because I cannot ask for federal assistance or state assistance, I cannot get that assistance. So I will face the penalty and I also cannot pay a plan that is \$200. I don't work and I am not a student. (Spanish-speaking consumer) 
There might be one person in Connect for Health, one on Medicaid, it makes it very complicated (Stakeholder)

\section{Lack of Culturally Competent Staff}

Spanish-speaking participants recounted a lack of bilingual staff at the government agencies where consumers were often directed to receive assistance. Consumers described, however, that in many cases even those who were bilingual did not provide respectful or culturally competent assistance or services.

In Denver, there are [health care] personnel that are compelled to reject Latinos. They treat people really badly, or do not make an effort to give people information. ... For me recently when I was [getting medical services] for my children, I went to an office in [another town] because of the poor treatment you get here in Denver. (Spanish-speaking consumer)

I wanted to see if [the clinic] could help my parents [get insurance]. They would tell us go to the Federal offices. And we would go and there's hardly anyone that speaks Spanish. (Spanish-speaking consumer) 


\section{Appendix B. Barriers to Health Insurance Coverage-North Central Region}

\section{Overview}

We conducted one focus group at a Connect for Health Colorado assistance site in the North Central region of Colorado (Fort Collins, Colorado), in order to capture information from Larimer, Weld, and Boulder counties. The focus group had 13 participants, and a significant percentage of participants were young adults aged 21 to 29. Most were female (69 percent), all were white, and 92 percent spoke only English at home. Only about 15 percent were married, but 46 percent had at least one child; 8 percent were employed full-time, and 30 percent reported being unemployed.

The average population in the region is 900,000 residents (approximately 300,000 residents in each county). Over 90 percent of the population is white (U.S. Census Bureau, 2013). Fort Collins, Colorado, is the most populous city in Larimer County and home to Colorado State University. Among the North Central population age 0-64, approximately 6.5 percent were Medicaid- or CHP+-eligible but not enrolled, and 5.3 percent qualified for tax credits in 2012 (Colorado Health Institute, 2014a). The North Central region had 60 percent of consumers who qualified for tax credit enroll in private insurance through the Marketplace (20 percent of the total number of Marketplace enrollments) and 55 percent of eligible consumers enroll in Medicaid (Colorado Department of Health Care Policy and Financing, April 2014a; Colorado Health Institute, 2014a). 
Figure B.1. North Central Region of Colorado and Location of Focus Groups (Fort Collins, Colorado)

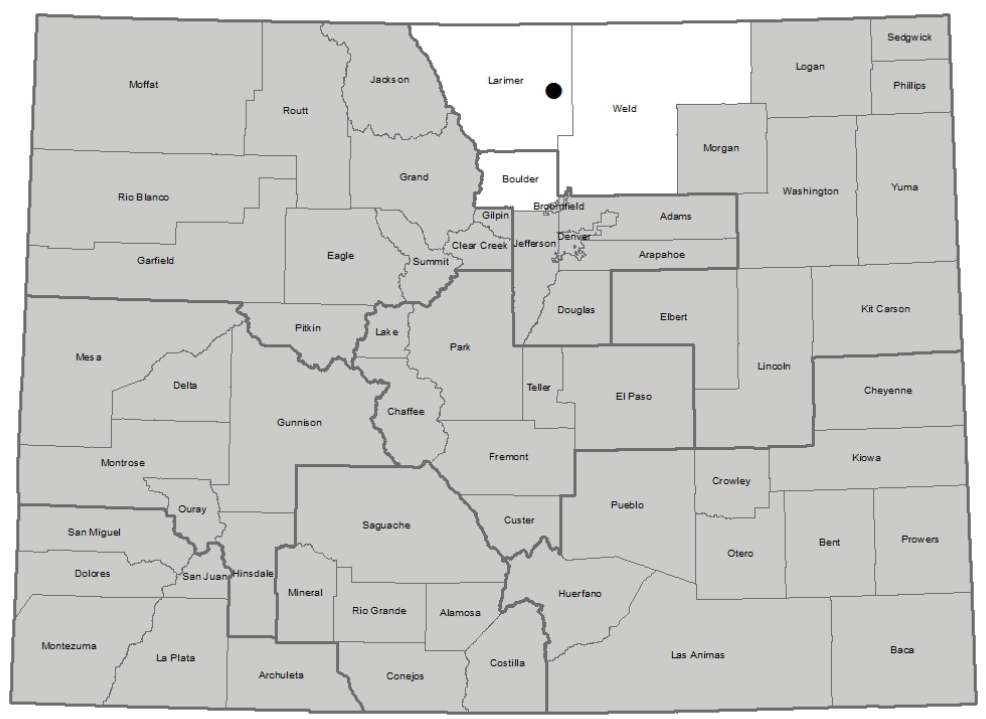

Of the barriers identified in Chapter Two, the following were discussed most often by consumers in the North Central region:

- Significant confusion and very little understanding about Medicaid and private insurance subsidies through the Marketplace

- Messaging about insurance was not compelling and did not discuss the health benefits of insurance

- Health insurance coverage is not affordable

- Complexity of materials makes plan selection difficult

- Misinformation across stakeholders.

Among consumers who had never had health insurance as adults, they were unaware that Medicaid did not require monthly premiums, were surprised at the cost of monthly premiums of private insurance through the Marketplace, felt overwhelmed by the number of choices in health insurance plan options without being able to distinguish what would be right for their individual or family circumstance, and preferred to seek non-preventative medical care from the Colorado Indigent Care Program (i.e., charitable care). Furthermore, first-time consumers attempted to complete health insurance applications by themselves, and discussed not being aware of where to go to get assistance or even knowing if they needed assistance (e.g., consumers were unaware of whether they had accurately completed the enrollment application).

One barrier specific to this region was a preference for complementary and alternative medical therapies. We also highlight the perspectives of young adults in this region. 
Table B.1. Barriers to Health Insurance Coverage in the North Central Region

\begin{tabular}{|c|c|c|c|}
\hline & Awareness & Decision to Enroll & Enrollment Process \\
\hline General & $\begin{array}{l}\text { Significant confusion } \\
\text { and very little } \\
\text { understanding about } \\
\text { Medicaid and private } \\
\text { insurance subsidies } \\
\text { through the Marketplace }\end{array}$ & $\begin{array}{l}\text { Unfavorable attitudes } \\
\text { toward the individual } \\
\text { mandate } \\
\text { - Significant mistrust in the } \\
\text { system } \\
\text { - Preference for holistic } \\
\text { therapies }\end{array}$ & $\begin{array}{ll}- & \text { Complexity of materials } \\
\text { makes plan selection difficult } \\
\text { - Young adults were } \\
\text { overwhelmed }\end{array}$ \\
\hline Messaging & $\begin{array}{l}\text { - Messaging consumers } \\
\text { were hearing about } \\
\text { insurance was not } \\
\text { compelling and did not } \\
\text { discuss the health } \\
\text { benefits of insurance }\end{array}$ & $\begin{array}{l}\text { Messaging was not often } \\
\text { tailored or actionable }\end{array}$ & $\begin{array}{l}\text { - Misinformation across } \\
\text { stakeholders }\end{array}$ \\
\hline Operational & $\begin{array}{l}\text { Not enough funds or } \\
\text { data to support local } \\
\text { outreach and education }\end{array}$ & $\begin{array}{l}\text { - Health insurance } \\
\text { coverage is not } \\
\text { affordable }\end{array}$ & $\begin{array}{l}\text { Lag times and poor } \\
\text { communication about } \\
\text { eligibility-related decisions } \\
\text { - } \quad \text { Must apply for Medicaid and } \\
\text { be denied before applying for } \\
\text { private insurance } \\
\text { - Connect for Health Colorado } \\
\text { website was not user-friendly }\end{array}$ \\
\hline
\end{tabular}

\section{Regional Barriers}

Given the proximity to Denver and the Metro region, few barriers specific to this region surfaced from either consumers or community stakeholders. However, a discussion of preference for holistic therapies as a potential barrier to enrollment was more prominent in this focus group than others, which may partially be due to complementary and alternative medicine and integrative medicine providers in the area.

\section{Preference for Complementary and Alternative Medical Therapies}

Consumers who had previously not had health care coverage discussed their preference for holistic or non-Western medical therapies, which are not necessarily covered by health insurance. These individuals resented having to be forced to buy health insurance that they felt they were not necessarily going to use, while still needing to pay out of pocket costs for their "natural" healers.

Honestly, it crossed my mind to ask why do I even have [health insurance]? I'm paying out of pocket and the integrative doctor costs $\$ 600$. (Consumer)

People may prefer natural remedies; that's normal for me. If I just had something to cover me for only catastrophic events for small price then I can do it. I teach people how to take care of themselves. I think we use health care for the smallest things - we overuse it. (Consumer) 


\section{Barriers for Young Adults}

Several young adults, ages 21-29 who were not able to be on their parent's insurance attempted to enroll in Medicaid. Young adults discussed feeling overwhelmed with trying to understand their health insurance plan options and recommended using online streaming services (e.g., Netflix, Pandora), shopping centers (e.g., Walmart, local grocery store), and colleges for students as more effective methods for outreach than newspapers, television, and radio.

I just turned 26-I had really good insurance because my mom works in a hospital and I was covered under her insurance. In the Marketplace, there were wide fluctuations in price and didn't know how to distinguish. (Consumer) 


\section{Appendix C. Barriers to Health Insurance Coverage-Northeast Region}

\section{Overview}

We conducted one focus group in the Northeast region of Colorado in Sterling, Colorado, with four participants who were residents of Logan and Yuma counties. All participants were female, white, and spoke English as their primary language in the home. One was employed full-time, while the others were currently unemployed. Two were married, and three had at least one child.

The Northeast region is consists of rural agriculture and industry-based communities with county populations that are less than 22,000 (Colorado Rural Development Council, 2014; U.S. Census Bureau, 2013). Among the Northeast population age 0-64, approximately 8.1 percent were Medicaid- or CHP+-eligible but not enrolled, and 4.7 percent qualified for tax credits in 2012 (Colorado Health Institute, 2014a). The Northeast region had 53 percent of consumers who qualified for tax credit enroll in private insurance through the Marketplace ( 2 percent of the total number of Marketplace enrollments) and 41 percent of eligible consumers enroll in Medicaid (Colorado Department of Health Care Policy and Financing, April 2014a; Colorado Health Institute, 2014a).

Figure C.1. Northeast Region of Colorado and Location of Focus Groups (Sterling, Colorado)

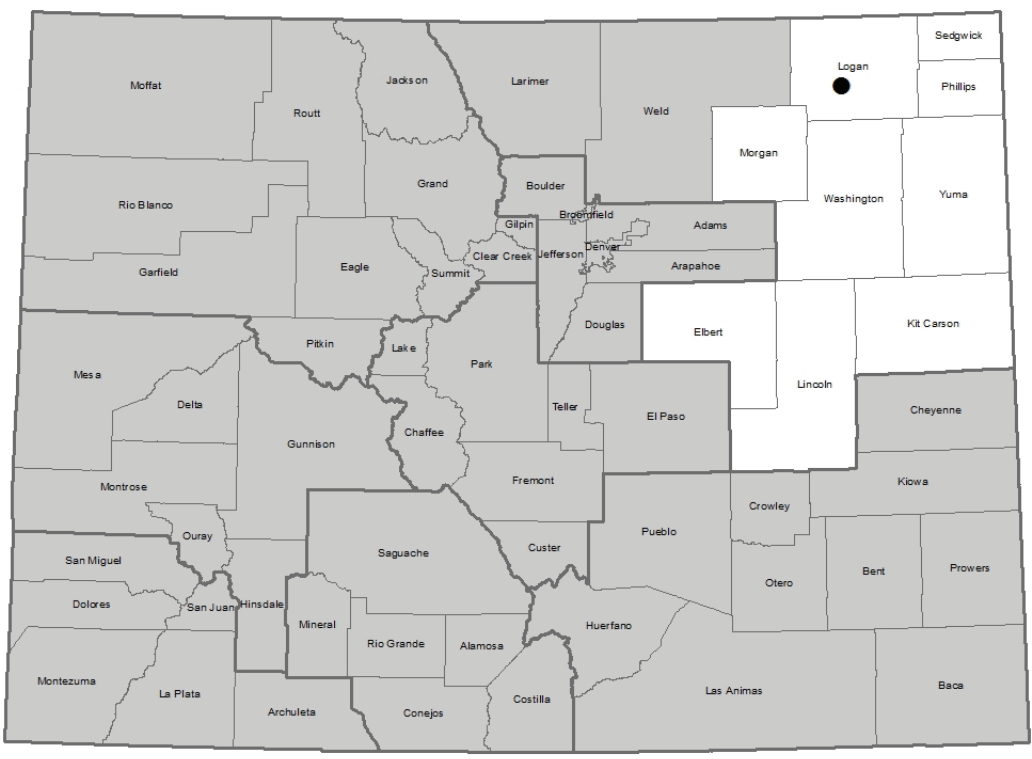


Of the barriers identified in Chapter Two, the following were discussed most often by consumers in the Northeast region:

- Unfavorable attitudes toward the individual mandate

- Significant mistrust in the system

- Messaging was not often tailored or actionable

- Must apply for Medicaid and be denied before applying for private insurance.

Three additional barriers that were especially prominent in this focus group of rural residents included conservative beliefs and stigma about government assistance programs, messaging from Denver that did not resonate with regional population, and a lack of incentive to enroll in health care coverage given the scarcity of health care providers, including dentists.

Table C.1. Barriers to Health Insurance Coverage in the Northeast Region

\begin{tabular}{|c|c|c|c|}
\hline & Awareness & Decision to Enroll & Enrollment Process \\
\hline General & $\begin{array}{l}\text { - Significant confusion } \\
\text { and very little } \\
\text { understanding about } \\
\text { Medicaid and private } \\
\text { insurance subsidies } \\
\text { through the } \\
\text { Marketplace }\end{array}$ & $\begin{array}{l}\text { - Unfavorable attitudes toward the } \\
\text { individual mandate } \\
\text { - Significant mistrust in the } \\
\text { system } \\
\text { - Conservative beliefs about } \\
\text { government assistance }\end{array}$ & $\begin{array}{l}\text { - Complexity of materials } \\
\text { makes plan selection } \\
\text { difficult }\end{array}$ \\
\hline Messaging & $\begin{array}{l}\text { - Messaging consumers } \\
\text { were hearing about } \\
\text { insurance was not } \\
\text { compelling and did not } \\
\text { discuss the health } \\
\text { benefits of insurance }\end{array}$ & $\begin{array}{l}\text { - Messaging was not often } \\
\text { tailored or actionable } \\
\text { - Messages from Denver did } \\
\text { not resonate }\end{array}$ & $\begin{array}{l}\text { - Misinformation across } \\
\text { stakeholders }\end{array}$ \\
\hline Operational & $\begin{array}{l}\text { - Not enough funds or } \\
\text { data to support local } \\
\text { outreach and } \\
\text { education }\end{array}$ & $\begin{array}{l}\text { - Health insurance coverage is } \\
\text { not affordable } \\
\text { - Scarcity of health care } \\
\text { providers and dentists }\end{array}$ & $\begin{array}{l}\text { Lag times and poor } \\
\text { communication about } \\
\text { eligibility-related } \\
\text { decisions } \\
\text { - } \text { Must apply for Medicaid } \\
\text { and be denied before } \\
\text { applying for private } \\
\text { insurance } \\
\text { Connect for Health } \\
\text { Colorado website was } \\
\text { not user-friendly }\end{array}$ \\
\hline
\end{tabular}

NOTE: Bold font indicates region-specific barriers not discussed in Chapter Two.

\section{Regional Barriers}

\section{Conservative Beliefs About Government Assistance}

In this region, there appears to be a heavy cultural stigma around using social services of any type, which includes Medicaid, regardless on one's need for these services. Consumers, for example, discussed a number of families who had to file for bankruptcy because of high-cost medical conditions and poor coverage from private insurance in the past. However, bankruptcy was viewed as a better alternative than being on a government assistance program. Despite 
recognition that there may be health-related benefits to Medicaid (i.e., free physical exam or coverage for medical supplies), participants agreed that most people would not want to share their Medicaid status with family or others in the community. Most participants attributed these feelings to the "frontier" mentality of the region, or a heavy reliable one one's self and neighbors. In this region, individuals did not necessarily want to qualify for Medicaid, so the process of needing to be ineligible for Medicaid in order to shop for private insurance in the Marketplace was a major obstacle among those who made an attempt to enroll.

One of the huge cultural markers here that's completely different than urban is the attitude toward entitlement. It is the opposite of Denver. Not same stigma there as is here. You pay bills on time, don't get into debt with local people, do what you say you're going to do, work for living, and best not to engage with social services. This is especially in the lawless town where there's no police at all. Our attitude is that we will take care of it with our family and ourselves. (Consumer)

Out further in South and East, people are not enrolled at all, and they are the people who never had health insurance and don't want government interference. If someone cuts finger off on the tractor they go home in the kitchen and sew it up. (Consumer)

People want to know what income to put so they do not qualify for Medicaid (Stakeholder)

\section{Messages from Denver Did Not Resonate}

Consumers relayed that the messages they received about Connect for Health Colorado or health care reform were not tailored to the community. Some residents felt that their views and lifestyles are not necessarily acknowledged or respected and resented messages that were from metropolitan areas (Denver).

They were airing ads that were really super targeted to young people that were showing skateboarders, skiers, and stuff like that. (Consumer)

When I lived in Denver, all we heard from this area is "you don't listen to us"; now that I live here, I can say "they don't listen to us." All of the television is from Denver, so people tune out. Channel 9 is only about Denver; our little community doesn't count. (Consumer)

\section{Lack of Providers and Dentists}

Health care and dental care may also be less of a priority in this region because of the scarcity of providers and the need to travel great distances to obtain specialty or dental care. Health insurance was seen as an additional barrier to obtaining health/dental care, given that some providers do not take certain health insurance, including Medicaid. This was a particular concern for consumers who had long-standing relationships with their health care provider.

There are no dental providers here. (Consumer) 
Providers are a major issue here. People want the physician that they have already have a relationship with - if they have to switch doctors, then they won't enroll. I know who people who had the same doctor for 10-15 years. (Consumer) 


\section{Appendix D. Barriers to Health Insurance Coverage-Central Region}

\section{Overview}

We conducted one focus group in the Central region of Colorado in the city of Colorado Springs (E1 Paso County). The focus group was composed of 13 participants. Individuals were between the ages of 22 and 63 years, with a median age of 49 years. The majority were female (69 percent), with at least some college (85 percent), though only about 15 percent were employed either full- or part-time. Just under a quarter were African American (23 percent), and 15 percent were Latino and spoke Spanish at home. About half (46 percent) were married, and 62 percent had at least one child. About a third (31 percent) were born outside of the United States but had lived in the United States for at least five years.

The Central region consists of El Paso, Park, Teller, Fremont, Lake, Chafee, and Custer counties. Colorado Springs in the second-most populous city in the state and home to military bases and the U.S. Air Force Academy. El Paso County has more than 655,000 residents, including racial/ethnic minorities (16 percent Hispanic origin, 7 percent African American, 3 percent Asian) (U.S. Census Bureau, 2013). Among the Central population age 0-64, approximately 7.8 percent were Medicaid- or CHP+-eligible but not enrolled, and 5.0 percent qualified for tax credits in 2012 (Colorado Health Institute, 2014a). The Central region had 35 percent of consumers who qualified for tax credit enroll in private insurance through the Marketplace ( 9 percent of the total number of Marketplace enrollments) and 51 percent of eligible consumers enroll in Medicaid (Colorado Department of Health Care Policy and Financing, April 2014a; Colorado Health Institute, 2014a). 
Figure D.1. Central Region of Colorado and Location of Focus Group (Colorado Springs, Colorado)

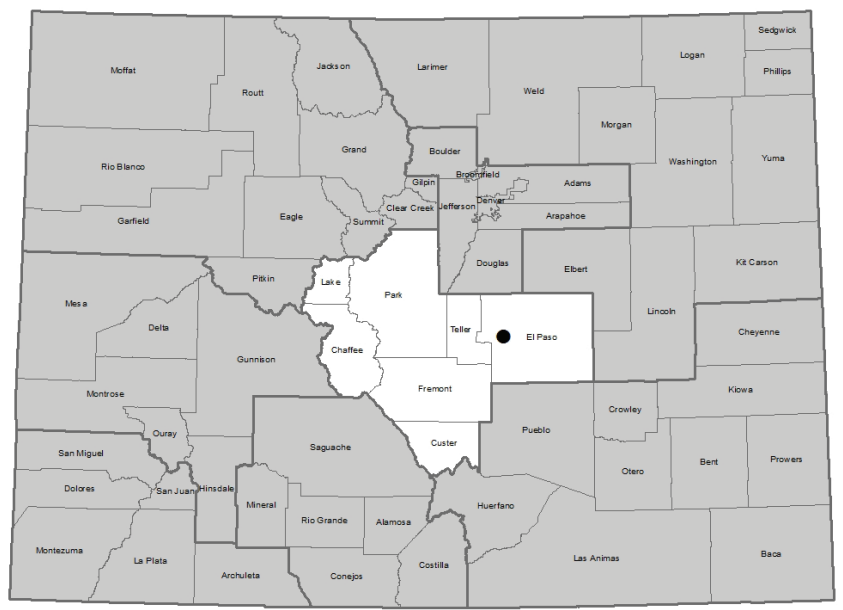

Of the barriers identified in Chapter Two, the following were discussed most often by consumers in the Central region:

- Significant confusion and very little understanding about Medicaid and private insurance subsidies through the Marketplace

- Messaging about insurance was not compelling and did not discuss the health benefits of insurance

- Unfavorable attitudes toward the individual mandate

- Health insurance is not affordable

- Misinformation across stakeholders

- Connect for Health Colorado website was not user-friendly.

One prominent regional barrier identified by this focus group was that linkages with other social service systems were weak and not leveraged sufficiently to support enrollment. 
Table D.1. Barriers to Health Insurance Coverage in the Central Region

\begin{tabular}{|c|c|c|c|}
\hline & Awareness & Decision to Enroll & Enrollment Process \\
\hline General & $\begin{array}{l}\text { - Significant confusion } \\
\text { and very little } \\
\text { understanding about } \\
\text { Medicaid and private } \\
\text { insurance subsidies } \\
\text { through the } \\
\text { Marketplace }\end{array}$ & $\begin{array}{l}\text { - Unfavorable attitudes toward the } \\
\text { individual mandate } \\
\text { - } \quad \text { Significant mistrust in the } \\
\text { system } \\
\text { - Linkages with other social } \\
\text { services systems were weak }\end{array}$ & $\begin{array}{l}\text { - Complexity of materials } \\
\text { makes plan selection } \\
\text { difficult }\end{array}$ \\
\hline Messaging & $\begin{array}{l}\text { - Messaging consumers } \\
\text { were hearing about } \\
\text { insurance was not } \\
\text { compelling and did not } \\
\text { discuss the health } \\
\text { benefits of insurance }\end{array}$ & $\begin{array}{l}\text { - Messaging was not often } \\
\text { tailored or actionable }\end{array}$ & $\begin{array}{l}\text { - Misinformation across } \\
\text { stakeholders }\end{array}$ \\
\hline Operational & $\begin{array}{l}\text { - Not enough funds or } \\
\text { data to support local } \\
\text { outreach and } \\
\text { education }\end{array}$ & $\begin{array}{l}\text { - Health insurance coverage is } \\
\text { not affordable }\end{array}$ & $\begin{array}{l}\text { - Lag times and poor } \\
\text { communication about } \\
\text { eligibility-related } \\
\text { decisions } \\
\text { - } \quad \text { Must apply for Medicaid } \\
\text { and be denied before } \\
\text { applying for private } \\
\text { insurance } \\
\text { Connect for Health } \\
\text { Colorado website was } \\
\text { not user-friendly }\end{array}$ \\
\hline
\end{tabular}

NOTE: Bold font indicates region-specific barriers not discussed in Chapter Two.

\section{Regional Barriers}

\section{Linkages with Other Social Service Systems Were Weak}

Social service and community-based agencies, such as workforce centers (employment agencies), food pantries, housing services, 2-1-1 information lines, and ecumenical social ministries, were seen as essential and trusted entities among community members. Consumer experiences were mixed with respect to staff from social service agencies providing accurate (or any) information on health care coverage and enrollment. While this barrier points to the misinformation provided by community stakeholders as noted in Chapter Two, it also points to missed opportunities for linkages between social service organizations and enrollment assistance sites. Consumers noted that such linkages could be strengthened to better support them during the enrollment process.

Some of those social workers don't give that information to their clients. My case manager didn't even know. They'll tell you that as an adult you can't apply for Medicaid because you don't have kids. (Consumer)

You can apply for Food Stamps and the subject about Medicaid will never come up. (Consumer) 


\section{Appendix E. Barriers to Health Insurance Coverage-Southeast Region}

\section{Overview}

We conducted one focus group in the Southeast region in Pueblo (Pueblo County). There were 11 focus group participants, and the majority (64 percent) had children eligible for health insurance coverage from Medicaid and $\mathrm{CHP}+$. The median age of participants was 34 years, 82 percent were female, 81 percent were white, and just under half were Hispanic (46 percent). About 9 percent spoke Spanish as the primary language in the home, and about a quarter were currently married (27 percent).

The Southeast region consists of ten counties and is home to the Comanche National Grassland. One-third of households in Pueblo, Colorado, have children under the age of 18 years old. Approximately 20 percent of the population in this region has household incomes below the FPL (U.S. Census Bureau, 2013). Among the Southeast population age 0-64, approximately 9.0 percent were Medicaid- or CHP+-eligible but not enrolled, and 5.9 percent qualified for tax credits in 2012 (Colorado Health Institute, 2014a). The Southeast region had 25 percent of consumers who qualified for tax credit enroll in private insurance through the Marketplace (2 percent of the total number of Marketplace enrollments) and 74 percent of eligible consumers enroll in Medicaid (Colorado Department of Health Care Policy and Financing, April 2014a; Colorado Health Institute, 2014a).

Figure E.1. Southeast Region of Colorado and Location of Focus Groups (Pueblo, Colorado)

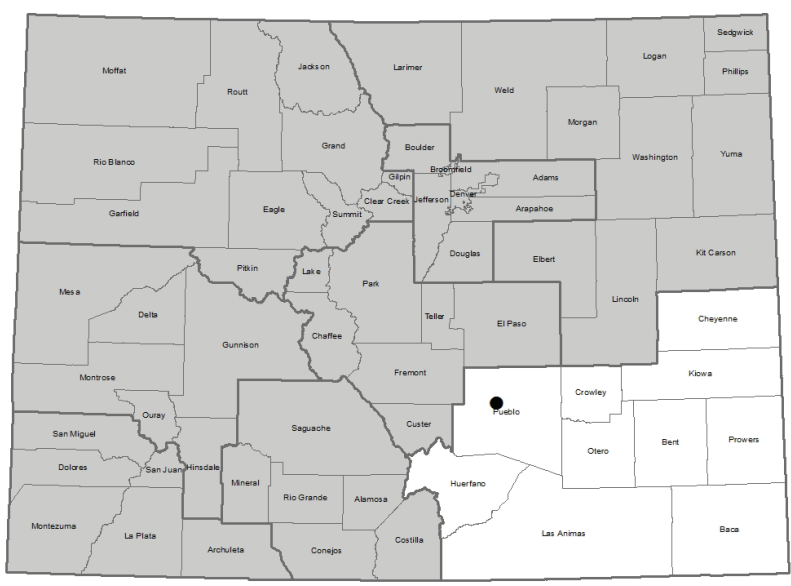


Of the barriers identified in Chapter Two, the following were discussed most often by consumers in the Central region:

- Significant confusion and very little understanding about Medicaid and private insurance subsidies through the Marketplace

- Messaging about insurance was not compelling and did not discuss the health benefits of insurance

- Health insurance is not affordable.

In contrast to other regions, consumers from this focus group provided the only positive experiences we heard with respect to enrollment and relayed fewer structural barriers. As a result, there are no additional barriers to report for this region. However, we describe below regional considerations that facilitated outreach and enrollment, including information dissemination to parents through community organizations that serve their children, more positive experiences with Medicaid and the enrollment process overall, and messaging that was more compelling and actionable. Given these more positive experiences, other regions may wish to further examine the approaches and lessons learned in and around Pueblo, particularly for Medicaid and CHP+ outreach and enrollment.

Table E.1. Barriers to Health Insurance Coverage in the Southeast Region

\begin{tabular}{|c|c|c|c|}
\hline & Awareness & Decision to Enroll & Enrollment Process \\
\hline General & $\begin{array}{l}\text { Significant confusion and } \\
\text { very little understanding } \\
\text { about Medicaid and } \\
\text { private insurance } \\
\text { subsidies through the } \\
\text { Marketplace }\end{array}$ & $\begin{array}{l}\text { - Unfavorable } \\
\text { attitudes toward the } \\
\text { individual mandate } \\
\text { - Significant mistrust } \\
\text { in the system }\end{array}$ & $\begin{array}{l}\text { - Complexity of materials } \\
\text { makes plan selection } \\
\text { difficult }\end{array}$ \\
\hline Messaging & $\begin{array}{l}\text { - Messaging consumers } \\
\text { were hearing about } \\
\text { insurance was not } \\
\text { compelling and did not } \\
\text { discuss the health } \\
\text { benefits of insurance }\end{array}$ & $\begin{array}{l}\text { Messaging was not } \\
\text { often tailored or } \\
\text { actionable }\end{array}$ & $\begin{array}{l}\text { Misinformation across } \\
\text { stakeholders }\end{array}$ \\
\hline Operational & $\begin{array}{l}\text { Not enough funds or data } \\
\text { to support local outreach } \\
\text { and education }\end{array}$ & $\begin{array}{l}\text { Health insurance } \\
\text { coverage is not } \\
\text { affordable }\end{array}$ & $\begin{array}{l}\text { - Lag times and poor } \\
\text { communication about } \\
\text { eligibility-related decisions } \\
\text { - Must apply for Medicaid } \\
\text { and be denied before } \\
\text { applying for private } \\
\text { insurance } \\
\text { Connect for Health } \\
\text { Colorado website was not } \\
\text { user-friendly }\end{array}$ \\
\hline
\end{tabular}




\section{Regional Considerations}

\section{Parents Were Reached Through Community Organizations Serving Their Children}

Parents in this group seemed to be more aware of the Medicaid expansion than those who were not parents. This could be because they were motivated to get their children insured, so in the process of enrolling their children they learned more about health care coverage for themselves. Parents of preschool-aged children also noted that they received information about health insurance through connections with organizations that serve their children. Head Start staff, for example, discussed Medicaid enrollment with parents. One parent noted that her Head Start family service worker gave her information about Medicaid when she found out that she had lost her job. Another parent mentioned that a staff person at a small health department located at a local high school handed her information about enrolling in health care coverage when she took her daughter to the school to receive immunizations. This parent was referred to the high school because her daughter needed the vaccines, but they did not yet have any insurance. These experiences point to the potential for community linkages to expand outreach and dissemination of health insurance information. Such experiences were not universal to all parents, however. More successful models of outreach to parents should be examined for adaptation or implementation on a wider scale.

\section{Positive Experiences with Medicaid}

Even though the group overall understood very little about Medicaid and private insurance subsidies through Connect for Health Colorado, participants expressed positive experiences with Medicaid, especially when it came to their children's coverage. In particular, participants revealed that they found Medicaid to be helpful and reported that "it's better than it was before" and "they cover more things than they did before." Parents noted in particular the value of prescription coverage, as well as dental and vision coverage.

\footnotetext{
One of my doctors explained Obamacare to me, and explained how here in Colorado a lot more people would be eligible than before. I asked him because I didn't really know; he looked at it as a positive thing, that a lot more people would qualify - just normal working people that didn't make enough can now get Medicaid, that's what he told me. (Consumer)

My kids always break their glasses, and Medicaid covers it — and I get six-month reminders for their appointments. (Consumer)

I think that the prescription coverage is a good thing, too-for Medicaid, it's one dollar, then free for children. Otherwise you're paying up to $\$ 70$. (Consumer)
}

\section{Positive Experiences with Enrollment}

Participants in this focus group expressed positive experiences with enrollment. This was the only region where we heard this sentiment and where we heard that the enrollment process was 
simple. One participant mentioned receiving direct outreach from a social worker when enrolling in Medicaid, suggesting that community stakeholders in this region have more consistent and accurate information and as a result appear to be supporting outreach and enrollment efforts in diverse ways.

It literally took me like five minutes, and [I] got approval right then and there. (Consumer)

A health coordinator from Medicaid called me. Just happened last year - my son is under his dad's [insurance coverage] as primary, and Medicaid as secondary. I got confused about my son's eligibility so I call her. She's local. I just call her and she was able to help me with eligibility questions. (Consumer)

\section{Some Messages Addressed Consumer Concerns and Were More Actionable}

Contrary to feedback from other regions, consumers in this focus group reported that the messages that reached them about the ACA and health insurance enrollment were compelling and more actionable. For example, after a rocky start to the open enrollment season, messages in this area noted that the Connect for Health Colorado website had been "fixed" and was now easier to use, helping to overcome concerns that consumers had about the efficacy of the enrollment process. Consumers also recalled messages stating that they could get phone assistance with enrollment if they called a number for help. 


\section{Appendix F. Barriers to Health Insurance Coverage-West Central Region}

\section{Overview}

We conducted two focus groups with a total of nine participants in the city of Grand Junction (Mesa County). One group consisted of parents with children eligible for Medicaid or CHP+. Participants had a median age of 34 years, and two-thirds (67 percent) were female. About half (56 percent) were unemployed. The majority of participants were white and non-Hispanic (89 percent), and all spoke English as their primary language. About 44 percent were married, and 55 percent had at least one child.

The West Central region of Colorado includes the counties west of the Continental Divide, such as Mesa, Delta, Montrose, Gunnison, Ouray, and Hinsdale. The terrain includes alpine meadows, canyons, plateaus, and high deserts and is home to the Grand Mesa, the world's highest flattop mountain. The regional population is rapidly growing, with major contributors to the economy from ranching, mining, health care, and tourism. Among the West Central population age 0-64, approximately 8.3 percent were Medicaid- or CHP+-eligible but not enrolled, and 8.5 percent qualified for tax credits in 2012 (Colorado Health Institute, 2014a). The West Central region had 36 percent of consumers who qualified for tax credit enroll in private insurance through the Marketplace ( 5 percent of the total number of Marketplace enrollments) and 58 percent of eligible consumers enroll in Medicaid (Colorado Department of Health Care Policy and Financing, April 2014a; Colorado Health Institute, 2014a).

Figure F.1. West Central Region of Colorado and Location of Focus Groups (Grand Junction, Colorado)

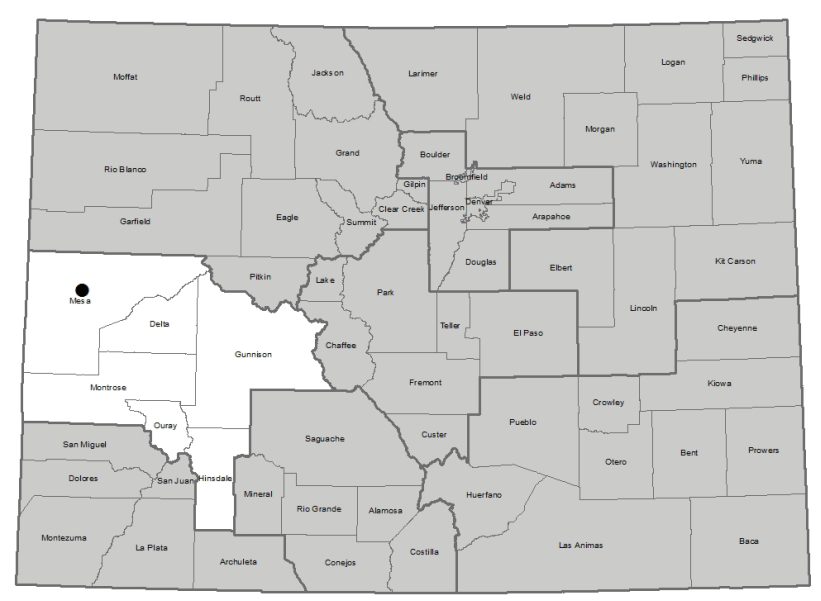


Of the barriers identified in Chapter Two, the following were discussed most often by consumers in the West Central region:

- Significant confusion and very little understanding about Medicaid and private insurance subsidies through the Marketplace

- Messaging about insurance was not compelling and did not discuss the health benefits of insurance

- Unfavorable attitudes toward the individual mandate

- Health insurance coverage is not affordable

- Complexity of materials makes plan selection difficult

- Lag times and poor communication about eligibility-related decisions.

Three additional regional considerations were especially prominent in this focus group: challenges understanding the difference between Colorado State Medicaid and Medicaid coverage offered by regional health plans, scarcity of health care providers, and limited Internet and computer access among residents.

Table F.1. Barriers to Health Insurance Coverage in the West Central Region

\begin{tabular}{|c|c|c|c|}
\hline & Awareness & Decision to Enroll & Enrollment Process \\
\hline General & $\begin{array}{l}\text { - Significant confusion } \\
\text { and very little } \\
\text { understanding about } \\
\text { Medicaid and private } \\
\text { insurance subsidies } \\
\text { through the } \\
\text { Marketplace }\end{array}$ & $\begin{array}{l}\text { - Unfavorable attitudes toward the } \\
\text { individual mandate } \\
\text { - Significant mistrust in the } \\
\text { system }\end{array}$ & $\begin{array}{l}\text { - Complexity of materials } \\
\text { makes plan selection } \\
\text { difficult }\end{array}$ \\
\hline Messaging & $\begin{array}{l}\text { - } \text { Messaging consumers } \\
\text { were hearing about } \\
\text { insurance was not } \\
\text { compelling and did not } \\
\text { discuss the health } \\
\text { benefits of insurance }\end{array}$ & $\begin{array}{l}\text { Messaging was not often } \\
\text { tailored or actionable }\end{array}$ & $\begin{array}{l}\text { - Misinformation across } \\
\text { stakeholders }\end{array}$ \\
\hline Operational & 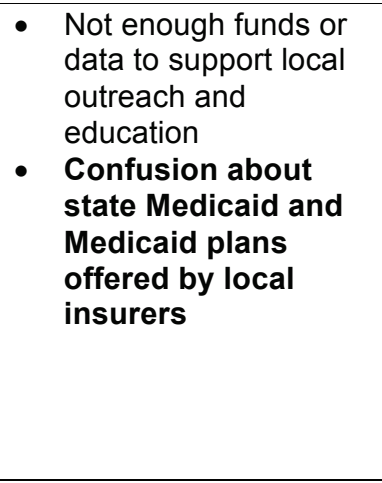 & $\begin{array}{l}\text { - Health insurance coverage is } \\
\text { not affordable } \\
\text { - Lack of providers and } \\
\text { dentists }\end{array}$ & $\begin{array}{l}\text { Lag times and poor } \\
\text { communication about } \\
\text { eligibility-related } \\
\text { decisions } \\
\text { - } \quad \text { Must apply for Medicaid } \\
\text { and be denied before } \\
\text { applying for private } \\
\text { insurance } \\
\text { Connect for Health } \\
\text { Colorado website was } \\
\text { not user-friendly } \\
\text { Internet/computer } \\
\text { access is limited }\end{array}$ \\
\hline
\end{tabular}

NOTE: Bold font indicates region-specific barriers not discussed in Chapter Two. 


\section{Regional Barriers}

\section{Confusion About State Medicaid and Medicaid Plans Offered by Local Insurers}

Participants in this region reported significant confusion about Medicaid coverage because they had heard that there were two types of Medicaid ("state-based Medicaid and HMO-based Medicaid"). It is likely that what they were referring to were different plan types within Medicaid, which can include:

- Accountable care collaborative programs, in which consumers receive Medicaid benefits plus coordinated care through a Regional Care Collaborative Organization

- Managed care organizations (MCOs), in which consumers have a primary care physician and see other providers within the MCO

- Regular Medicaid, in which members can go to any doctor, clinic, hospital, or pharmacy that takes Medicaid (Colorado Department of Health Care Policy and Financing, 2014b).

Participants explained that the majority of providers in the area accepted only HMO-based Medicaid, and those who were trying to transfer to HMO-based Medicaid were experiencing difficulties with obtaining this type of Medicaid. One participant mentioned that when she tried to enroll in the HMO-based Medicaid, she called the state-based Medicaid representatives who told her that they do not handle HMO-based Medicaid.

I just received information a few weeks ago that the medical cards (HMO and State) are the same, but it can't be. (Consumer)

These findings point to a real need to clarify different plan options within Medicaid, particularly in regions where MCOs are available options, and to help consumers enroll in the Medicaid plan that best meets their needs and preferences.

\section{Lack of Providers and Dentists}

Participants expressed that there are few providers and dentists in the area, and even fewer who accept Medicaid. While one uninsured participant stated that her doctor would keep her as a patient even if she enrolls in Medicaid because she was always her patient, a newly insured participant expressed concerns about finding a new doctor because his current doctor does not accept Medicaid.

My husband went to the doctor, but then when the doctor found out that he had Medicaid, the said [in a snappy voice] "Well, what do you want me to do with you?" (Consumer)

\section{Internet/Computer Access Is Limited}

Participants mentioned that limited computer connectivity is one of the main reasons that that people have not enrolled in health care coverage. Participants stated that Internet is expensive in the area, but that coffee shops, some fast food restaurants, and the library offer free Wi-Fi. 
Participants also said that many people in the community do not own or know how to use computers. This barrier points to the need for dissemination about the availability of phone-based or in-person assistance, particularly in rural areas where a lack of Internet connectivity may pose a logistical barrier. 


\section{Appendix G. Barriers to Health Insurance Coverage-Northwest Region}

\section{Overview}

We conducted two focus groups in Silverthorne, Colorado (Summit County), with a total of 13 participants. One group represented views from English-speaking seasonal and small business workers, and the other group consisted of Spanish-speaking residents. The median age was 38 years, 85 percent were female, and about 45 percent were employed either full- or part-time. About three-quarters were white ( 77 percent), and over half were Latino ( 54 percent), all of whom spoke Spanish as their primary language. This region had the highest proportion of individuals who were married (92 percent), and just over half had one or more children (55 percent). About two-thirds (62 percent) were born outside of the United States, and 15 percent spend only part of the year in Summit County. Of these individuals, all reported that they lived in Summit County for about four months out of the year.

The Northwest region of Colorado is famous for its recreational activities and has a number of mountain ski resorts, whitewater rivers, sandstone canyons, and alpine lakes. The rural region includes Summit, Eagle, Pitkin, Grand, Jackson, Routt, Moffat, Rio Blanco, Clear Creek, Gilpin, and Garfield counties. Among the Northwest population age 0-64, approximately 7.4 percent were Medicaid- or $\mathrm{CHP}+$-eligible but not enrolled, and 6.5 percent qualified for tax credits in 2012 (Colorado Health Institute, 2014a). The Northwest region had 52 percent of consumers who qualified for tax credit enroll in private insurance through the Marketplace ( 7 percent of the total number of Marketplace enrollments) and 34 percent of eligible consumers enroll in Medicaid (Colorado Department of Health Care Policy and Financing, April 2014; Colorado Health Institute, 2014a). 
Figure G.1. Northwest Region of Colorado and Location of Focus Groups (Silverthorne, Colorado)

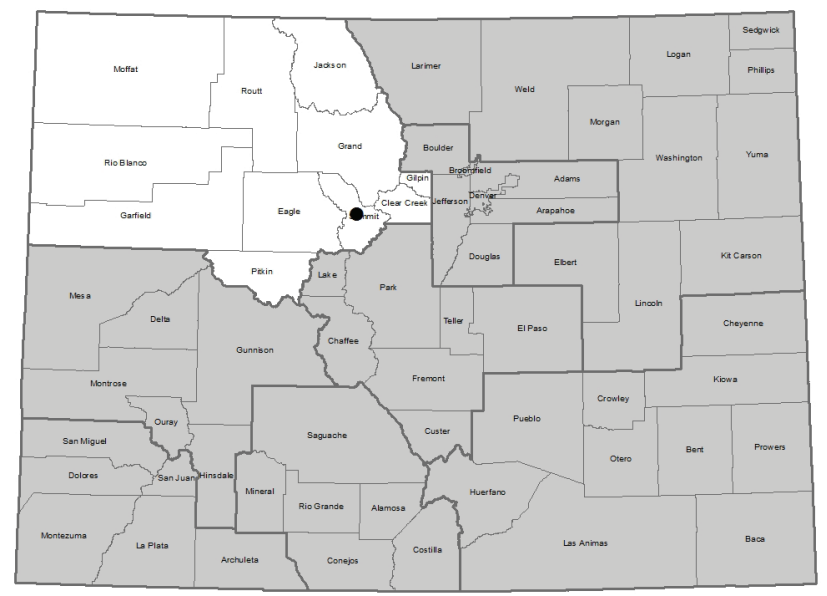

Of the barriers identified in Chapter Two, the following were discussed most often by consumers in the Northwest region:

- Significant confusion and very little understanding about Medicaid and private insurance subsidies through the Marketplace

- Significant mistrust in the government

- Health insurance coverage is not affordable

- Must apply for Medicaid and be denied before applying for private insurance.

One regional consideration that was especially prominent in the focus groups was the experience that coverage options such as COBRA were more affordable than other forms of health insurance. We also highlight barriers discussed by two special populations: seasonal workers and Spanish-speaking Latinos. 
Table G.1. Barriers to Health Insurance Coverage in the Northwest Region

\begin{tabular}{|c|c|c|c|}
\hline & Awareness & Decision to Enroll & Enrollment Process \\
\hline General & $\begin{array}{l}\text { Significant confusion } \\
\text { and very little } \\
\text { understanding about } \\
\text { Medicaid and private } \\
\text { insurance subsidies } \\
\text { through the } \\
\text { Marketplace }\end{array}$ & $\begin{array}{l}\text { - Unfavorable attitudes toward } \\
\text { the individual mandate } \\
\text { - Significant mistrust in the } \\
\text { system } \\
\text { - Time-consuming and more } \\
\text { expensive for seasonal } \\
\text { workers } \\
\text { - Lack of culturally competent } \\
\text { and respectful health care } \\
\text { staff }\end{array}$ & $\begin{array}{l}\text { - Complexity of materials } \\
\text { makes plan selection } \\
\text { difficult }\end{array}$ \\
\hline Messaging & $\begin{array}{l}\text { - Messaging consumers } \\
\text { were hearing about } \\
\text { insurance was not } \\
\text { compelling and did not } \\
\text { discuss the health } \\
\text { benefits of insurance } \\
\text { - Lack of messaging in } \\
\text { ethnic media }\end{array}$ & $\begin{array}{l}\text { Messaging was not often } \\
\text { tailored or actionable }\end{array}$ & $\begin{array}{l}\text { - } \begin{array}{l}\text { Misinformation across } \\
\text { stakeholders }\end{array}\end{array}$ \\
\hline Operational & $\begin{array}{l}\text { - Not enough funds or } \\
\text { data to support local } \\
\text { outreach and } \\
\text { education }\end{array}$ & $\begin{array}{l}\text { - Health insurance coverage is } \\
\text { not affordable } \\
\text { - COBRA is a more affordable } \\
\text { option }\end{array}$ & $\begin{array}{l}\text { - Lag times and poor } \\
\text { communication about } \\
\text { eligibility-related } \\
\text { decisions } \\
\text { - Must apply for Medicaid } \\
\text { and be denied before } \\
\text { applying for private } \\
\text { insurance } \\
\text { Connect for Health } \\
\text { Colorado website was } \\
\text { not user-friendly } \\
\text { Monthly vs. annual } \\
\text { income eligibility } \\
\text { creates challenges for } \\
\text { seasonal workers }\end{array}$ \\
\hline
\end{tabular}

NOTE: Bold font indicates region-specific barriers not discussed in Chapter Two.

\section{Regional Barriers}

\section{COBRA Is a More Affordable Option}

This region has one of the most expensive premiums for health insurance in the country. It is therefore not surprising that participants noted that the cost of health insurance was a major barrier in their decision to enroll. Though premiums in this region were recently lowered to address this barrier, consumers felt that the reduction was not substantial enough to change their decision about enrollment - even with this reduction the cost was perceived as too high. Several participants noted that COBRA was seen as a more affordable option, estimating that it was about \$200-\$250 cheaper per month than premiums offered through the Marketplace. The lack of affordable insurance and the inability for consumers to get tax credits was seen as a major barrier to enrollment. 
I don't think it's rare up here that COBRA cost less than private insurance, unless you qualify for the tax credit (Consumer)

50 percent of people are above 450 percent Federal poverty level and can't afford insurance. Lots of uninsured. Many small business owners are in this group and they cannot afford insurance. They can't get any tax credits (Stakeholder)

One analysis showed, however, that while premiums in this area may be 60-70 percent higher than in other regions without subsidies, with tax credits, the premiums are lower than corresponding rates in Denver (Brown, 2013). Many adults may qualify for tax credits in these areas but may not be aware of this eligibility, suggesting the need to examine the effectiveness of outreach and messaging related to health insurance subsidies.

\section{Barriers for Seasonal Workers}

\section{Time-Consuming and More Expensive for Seasonal Workers}

One of the challenges that seasonal workers noted is that they do not know how to obtain or maintain coverage once their job ends for the season. A participant who is a seasonal worker revealed that her Human Resources manager referred her to a local assistance site to receive help with enrollment.

I have Medicaid now, but I didn't know what I was going to do when my job was over. I thought about it a lot because it was a difficult thing even before the reform. I think learning about coverage during human resource orientations would have really helped a lot, but they don't have human resources staff for those things. [When I was working] I took [employers insurance] because it was cheaper and less time-consuming than going through the Marketplace. [When my job ended] I had to take my own initiative to go and find out [about health insurance], and I wasn't quite sure what to do. (Consumer)

The frequent switching of health insurance plans throughout the year due to changes in employment often results in needing to pay more than one deductible in a year. For example, participants cited a seasonal worker who may require surgery early in the year and who paid his $\$ 3,000$ deductible, subsequently lost his seasonal job and obtained Medicaid while he was unemployed, but then obtained new private insurance coverage when he was employed again that same year with a new $\$ 3,000$ deductible. Therefore, some seasonal workers found that staying on COBRA made more financial sense.

The need to regularly reevaluate health insurance coverage options was considered timeconsuming and confusing and resulted in a number of consumers "giving up" and choosing not to enroll in health care coverage. In addition, participants noted that there were a limited number of assisters in this region, and they were only able to help consumers with more complex situations. 


\section{Monthly Versus Annual Income Eligibility Creates Challenges for Seasonal Workers}

Another challenge that seasonal workers face is that their annual earnings for the year is often earned over several months. This poses a challenge because eligibility for Medicaid and subsidies for private insurance are calculated differently: Medicaid eligibility is determined on monthly income, while eligibility for subsidized private insurance through the Marketplace is based on annual income. Therefore, a seasonal worker may earn $\$ 75,000$ in six months, but if an individual were to obtain health care coverage in the off-season, then he or she would qualify for Medicaid. Seasonal workers often have a difficult time estimating projected income for the upcoming year. While they can report on what they earned last year, there is less job security, making eligibility-related paperwork difficult to complete.

\section{Barriers for Spanish-Speaking Latinos}

\section{Lack of Messaging in Ethnic Media}

English-speaking groups universally heard about health care reform, Medicaid, or Connect for Health Colorado through some type of media, as well as the new legislation to reduce insurance premiums in the region. However, the Latino participants in the Spanish-speaking focus group were less aware of health care reform and not aware of the new legislation. Most participants indicated that they widely listen to the radio, but that the radio was for entertainment and not a source for conveying news or important health information.

They should be announcing this like crazy because it is really important. (Spanish-speaking consumer)

I have never heard of this. We are so badly informed. (Spanish-speaking consumer)

On the other hand stakeholders acknowledged that of all the methods of outreach for Latino populations, media was most effective. Television and radio was perceived as reaching a greater proportion of the population than other modes of outreach, such as social media. This lack of messaging coupled with continued concerns about the high cost of care points to a need to strengthen outreach and messaging in this area to the Spanish-speaking population in particular.

\section{Lack of Culturally Competent and Respectful Health Care Staff}

Participants discussed negative experiences with the health care system, mainly in terms of interactions with bilingual Latino front office or administrative staff. These interactions made a number of participants hesitant to seek medical attention for themselves or their family members. Participants also discussed the need for health care systems to hire culturally competent, and not just bilingual, staff. These barriers extended to health insurance carriers as well. 
They should also not hire people just because they are bilingual, they should have skills that make you feel comfortable and they should treat you nicely because that is their job. (Spanish-speaking consumer)

Insurance carriers need to be culturally and linguistically responsible.

(Stakeholder) 


\section{Appendix H. Barriers to Health Insurance Coverage-Southwest Region}

\section{Overview}

We conducted four interviews with residents in Durango, Colorado. Interviews were conducted in lieu of a focus group because participants were unable to meet at the designated date and time, but were still interested in sharing their perspectives. The median age of participants was 38 years, half of whom were female. All were white, non-Hispanic and spoke primarily English in the home. Half were currently married, but all had at least one child.

The Southwest region of Colorado includes La Plata, San Juan, San Miguel, Dolores, Montezuma, and Archuleta counties. This is a mainly rural region with populations less than 50,000 residents per county (U.S. Census Bureau, 2013). Among the Southwest population age 0-64, approximately 9.1 percent were Medicaid- or CHP+-eligible but not enrolled, and 11.7 percent qualified for tax credits in 2012 (Colorado Health Institute, 2014a). The Southwest region had 38 percent of consumers who qualified for tax credit enroll in private insurance through the Marketplace ( 3 percent of the total number of Marketplace enrollments) and 53 percent of eligible consumers enroll in Medicaid (Colorado Department of Health Care Policy and Financing, April 2014; Colorado Health Institute, 2014a).

Figure H.1. Southwest Region of Colorado and Location of Interviews (Durango, Colorado)

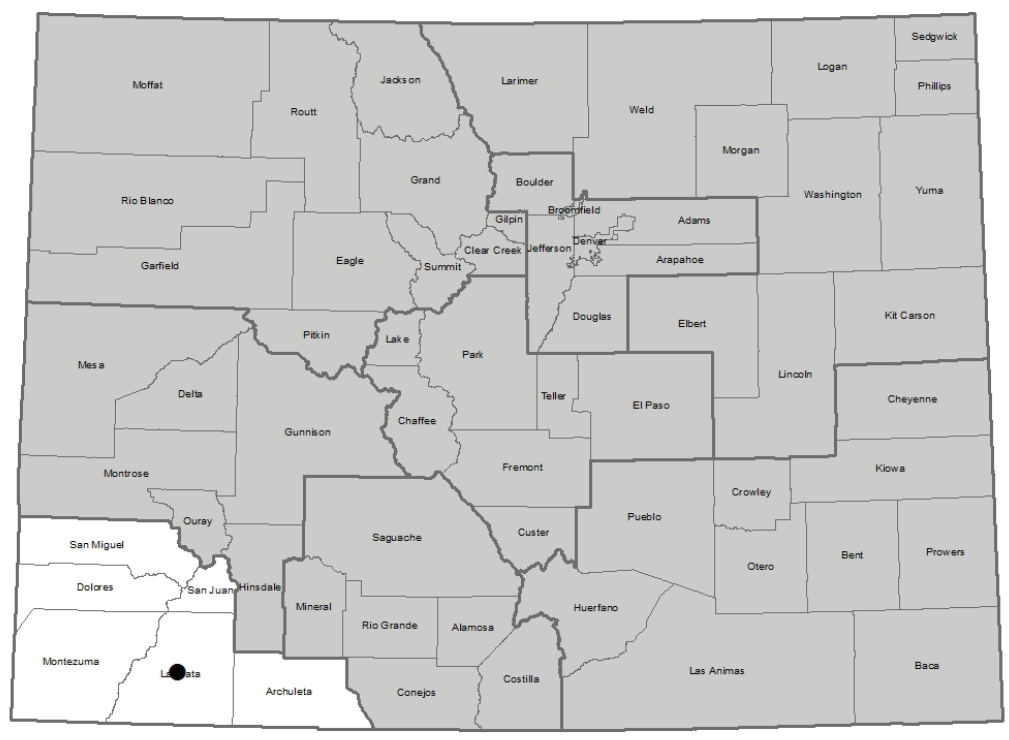


Of the barriers identified in Chapter Two, the following were discussed most often by consumers in the Northwest region:

- Messaging about insurance was not compelling and did not discuss the health benefits of insurance

- Messaging was not often tailored or actionable

- Health insurance coverage is not affordable

- Misinformation across stakeholders

- Must apply for Medicaid and be denied before applying for private insurance.

One regional consideration that was especially prominent in this region was limited information about where to go for enrollment assistance.

Table H.1. Barriers to Health Insurance Coverage in the Southwest Region

\begin{tabular}{|c|c|c|c|}
\hline & Awareness & Decision to Enroll & Enrollment Process \\
\hline General & $\begin{array}{l}\text { Significant confusion } \\
\text { and very little } \\
\text { understanding about } \\
\text { Medicaid and private } \\
\text { insurance subsidies } \\
\text { through the } \\
\text { Marketplace }\end{array}$ & $\begin{array}{l}\text { - Unfavorable attitudes toward the } \\
\text { individual mandate } \\
\text { - Significant mistrust in the } \\
\text { system }\end{array}$ & $\begin{array}{l}\text { - Complexity of materials } \\
\text { makes plan selection } \\
\text { difficult }\end{array}$ \\
\hline Messaging & $\begin{array}{l}\text { - Messaging consumers } \\
\text { were hearing about } \\
\text { insurance was not } \\
\text { compelling and did not } \\
\text { discuss the health } \\
\text { benefits of insurance }\end{array}$ & $\begin{array}{l}\text { - Messaging was not often } \\
\text { tailored or actionable }\end{array}$ & $\begin{array}{l}\text { - Misinformation across } \\
\text { stakeholders } \\
\text { - Limited information } \\
\text { about where to go for } \\
\text { enrollment assistance }\end{array}$ \\
\hline Operational & $\begin{array}{l}\text { - Not enough funds or } \\
\text { data to support local } \\
\text { outreach and } \\
\text { education }\end{array}$ & $\begin{array}{l}\text { - Health insurance coverage is } \\
\text { not affordable }\end{array}$ & $\begin{array}{l}\text { - Lag times and poor } \\
\text { communication about } \\
\text { eligibility-related } \\
\text { decisions } \\
\text { - } \text { Must apply for Medicaid } \\
\text { and be denied before } \\
\text { applying for private } \\
\text { insurance } \\
\text { Connect for Health } \\
\text { Colorado website was } \\
\text { not user-friendly }\end{array}$ \\
\hline
\end{tabular}

NOTE: Bold font indicates region-specific barriers not discussed in Chapter Two.

Consumers that we spoke to in this region were somewhat unique in that they were workingclass individuals, who were fairly well educated, but struggling with insurance enrollment. Several had experienced wide shifts in insurance-related costs (increases of $\$ 400-\$ 600$ per month) as a result of the implementation of the ACA, and others had been dropped from their insurance carriers and were struggling to find affordable options. It is not clear whether there is something specific to this region that was causing these shifts, such as a higher prevalence of health plans that did not meet core requirements put forth under the ACA, or whether this was a function of the sample of individuals who participated, but this was the only region where these issues were raised. 


\section{Regional Barriers}

\section{Limited Information About Where to Go for Enrollment Assistance}

Experiences of consumers in this region further highlight many of the universal barriers noted in Chapter Two, but one issue was particularly salient in this region-the lack of any information about where to go for assistance with enrollment. While we note in earlier sections of the report that messages need to be more actionable to facilitate linkages with the agencies that can support decisionmaking and enrollment, here consumers noted that even after specific Internet searches, they were not able to identify assistance sites. This further reiterates the need for expansion of outreach and marketing budgets for local assistance sites. Consumer connections to organizations that could help with enrollment occurred by chance or by word of mouth after reaching out to friends or family. Somewhat concerning is that these are stories of uninsured individuals who persevered simply because they felt health insurance was important, and had the skills and abilities to pursue multiple avenues, even though it took a significant amount of time and energy.

I was in a mode of panic, I called individual insurance companies where I get home insurance and car insurance. Then I called another broker and he was giving me options that were not compliant with Obamacare and I was not aware that you could get a plan that was not compliant and I was on wild goose chase to get competitive rates. (Consumer)

I'm fairly educated I can only imagine what it is like for folks who can't read well. If I had known to go [to the community resource center] first it would have been a cinch, but there was no information out there that I could find. I would have never known. You should make sure those resources are known-they are available and they are great. For as good as she was there should have been a line out the door and if people knew about her it would have been that way. There is no pressure, they can get you on the right path and they don't have a stake in the game. (Consumer) 


\section{References}

Brown, K. (2013). After Tax Credits, Many Insurance Plans in Garfield, Summit Counties Are Less Expensive Than Those in Denver. Denver, CO: Colorado Center on Law and Policy. As of August 21, 2014:

http://cclponline.org/wp-content/uploads/2013/12/Summit-vs-Denver-fact-sheet-final.pdf

Camarota, S. A. (August 2012). Immigrants in the United States, 2010: A Profile of America's Foreign-Born Population. Washington, CD: Center for Immigration Studies. As of August 21, 2014: http://cis.org/2012-profile-of-americas-foreign-born-population

Centers for Medicare and Medicaid Services. (2014a). Fact Sheet: Helping Consumers Apply and Enroll Through the Marketplace. As of August 21, 2014:

http://www.cms.gov/CCIIO/Resources/Fact-Sheets-andFAQs/Downloads/AssistanceRoles_06-10-14-508.pdf

Centers for Medicare and Medicaid Services. (2014b). In-Person Assistance in the Health Insurance Marketplace. As of August 21, 2014:

http://www.cms.gov/CCIIO/Programs-and-Initiatives/Health-Insurance-

Marketplaces/assistance.html

Child Health Plan Plus. (2014). About CHP+. As of August 21, 2014: http://cchp.org/index.cfm?action=aboutCHP\&language=eng

Colorado Department of Health Care Policy and Financing. (2013). Adults without Dependent Children 1115 Demonstration Waiver: Medicaid Expansion Transition Plan. Denver, CO. As of August 21, 2014: http://cchn.org/wp-content/uploads/2013/09/CO-AwDC-Transition-Plan-final.pdf

Colorado Department of Health Care Policy and Financing. (April 2014a). Medicaid Expansion Update. As of August 21, 2014:

http://www.colorado.gov/cs/Satellite?blobcol=urldata\&blobheader=application \%2Fpdf\&blo $\underline{\text { bkey }=\text { id\&blobtable }=\text { MungoBlobs \&blobwhere }=1251968658803 \& \text { ssbinary }=\text { true }}$

Colorado Department of Health Care Policy and Financing. (2014b). Medicaid Managed Care FAQ. As of August 21, 2014:

http://www.colorado.gov/cs/Satellite/HCPF/HCPF/1213954074883\#what health plans are offered 
Colorado Department of Public Health and Environment. (2014). Yellow Fever Vaccine Providers in Colorado. As of August 21, 2014:

http://www.colorado.gov/cs/Satellite/CDPHE-DCEED/CBON/1251611183161

Colorado Department of Regulatory Agencies (DORA), Division of Insurance. (2014). Health Insurance Premiums Approved for Plans in 2014. As of August 21, 2014:

http://cdn.colorado.gov/cs

Colorado Health Institute. (2014a). Colorado Eligibility Atlas: Mapping the Uninsured. As of August 21, 2014:

http://coloradohealthinstitute.org/data-repository/category/colorado-health-access-survey

Colorado Health Institute. (2014b). How Many Uninsured Adults Are Eligible for Medicaid? As of August 21, 2014:

http://www.coloradohealthinstitute.org/uploads/postfiles/EBNE/2014_EBNE_Adults_Fact_S heet.pdf

Colorado Rural Development Council (CRDC). (2014). Homepage. As of August 21, 2014: http://www.ruralcolorado.org/

Colorado Trust. (2013). Young Invincibles? Why Young Adults Have Colorado's Highest Uninsurance Rate. Denver, CO. As of August 21, 2014:

http://www.coloradotrust.org/attachments/0001/9634/CHAS_YoungInvinciblesBrief_vF.pdf

Connect for Health Colorado. (April 2014). By the Numbers: The First Open Enrollment of Connect for Health Colorado, October 2013 Through March 2014. Denver, CO. As of August 21, 2014:

http://connectforhealthco.com/wp-content/uploads/2014/04/FINAL-data-open-enrollmentreport-4-14-144.pdf

Connect for Health Colorado. (May 2014). Marketplace Dashboard. Denver, CO. As of August 21, 2014:

http://connectforhealthco.com/wp-content/uploads/2014/06/Marketplace-Dashboard-05-312014.pdf

Connect for Health Colorado. (2013). Connect for Health Assistance Network: Update on Assistance Network Grantees. Denver, CO. As of August 21, 2014:

http://www.connectforhealthco.com/?wpfb_dl=735

Courtot, B., \& Coughlin, T. (2013). ACA Implementation-Monitoring and Tracking: CrossCutting Issues: Progress in Implementing Selected Medicaid Provisions of the Affordable Care Act: A 10-State Analysis. Washington, D.C.: The Urban Institute. 
Dash, S., Lucia, K., Keith, K., \& Monahan, C. (2013). Implementing the Affordable Care Act: Key Design Decisions for State-Based Exchanges. Washington, D.C.: The Commonwealth Fund.

James, K. (2014). How Did Two Circuits Come to Differeing Conclusions on ACA Subsidies? Inside Counsel. As of August 21, 2014:

http://www.insidecounsel.com/2014/08/12/how-did-two-circuits-come-to-differingconclusions

Kaiser Family Foundation. (2014). Status of State Medicaid Expansion as of 2014. As of August 21, 2014:

http://kff.org/health-reform/state-indicator/state-activity-around-expanding-medicaid-underthe-affordable-care-act/

Kaiser Family Foundation. (April 2013). Summary of the Affordable Care Act. As of August 21, 2014: http://kaiserfamilyfoundation.files.wordpress.com/2011/04/8061-021.pdf

Kaiser Family Foundation. (April 2014a). Heath Reform Fact Sheet: How Will the Uninsured Fare Under the Affordable Care Act. As of August 21, 2014:

http://kff.org/health-reform/fact-sheet/how-will-the-uninsured-fare-under-the-affordablecare-act/

Kaiser Family Foundation. (April 2014b). Marketplace Enrollment as a Share of Potential Marketplace Population. As of August 21, 2014:

http://kff.org/health-reform/state-indicator/marketplace-enrollment-as-a-share-of-thepotential-marketplace-population/

Kaiser Family Foundation. (November 2013). State Marketplace Profiles: Colorado. As of August 21, 2014:

http://kff.org/health-reform/state-profile/state-exchange-profiles-colorado/

Kaiser Health News, Kaider Family Foundation. (February 3, 2014). The 10 Most Expensive Insurance Markets in the U.S. As of August 21, 2014:

http://www.kaiserhealthnews.org/stories/2014/february/03/most-expensive-insurancemarkets-obamacare.aspx

Krippendorff, K. (2012). Content Analysis: An Introduction to Its Methodology. New York: Sage.

National Immigration Law Center. (2014). Immigrants and the Affordable Care Act (ACA). Los Angeles, CA. As of August 21, 2014:

http://www.nilc.org/immigrantshcr.html 
RAND Corporation. (2014). The Affordable Care Act: Four key Policy Areas. As of August 21, 2014:

http://www.rand.org/health/aca.html\#state-exchanges

Shartzer, A., Kenney, G., Long, S., Hempstead, K., \& Wissoker, D. (2014). Who Are the Remaining Uninsured as of June 2014? Washington, D.C.: The Urban Institute.

U.S. Census Bureau. (2013). State and County QuickFacts. As of August 21, 2014: http://quickfacts.census.gov/qfd/states/08000.html

U.S. Department of Health and Human Services, Office of the Assistant Secretary for Planning and Evaluation. (2014). Profile of Affordable Care Act Coverage Expansion Enrollment for Medicaid/CHIP and the Health Insurance Marketplace: 10-1-2013 to 3-31-2014: Colorado. Washington, DC. As of August 21, 2014:

http://aspe.hhs.gov/health/reports/2014/marketplaceenrollment/apr2014/pdf/co.pdf 